\title{
Procedimentos e critérios para zoneamento de planícies de inundação em áreas urbanas
}

\author{
Procedures and criteria for floodplain regulation in urban \\ areas
}

Dante Gama Larentis ${ }^{1}$, Marianni Nogare 2, Carlos Eduardo Morelli Tucci ${ }^{3}$ (D) Patricia Pohlmann ${ }^{4}$

${ }^{1}$ Acqua Engenharia de Recursos Hídricos. Porto Alegre, RS, Brasil. E-mail: dantelarentis@gmail.com

${ }^{2}$ The University of British Columbia - Okanagan Campus, Kelowna, BC, Canadá. E-mail: marianni.nogare@gmail.com

${ }^{3}$ Rhama Consultoria Ambiental. Porto Alegre, RS, Brasil E-mail: carlos.tucci@rhama.com.br

${ }^{4}$ Universidade de Caxias do Sul, Caxias do Sul, RS, Brasil. E-mail: patricia.arquitetura@gmail.com

Como citar: Larentis, D. G., Nogare, M., Tucci, C. E. M., Pohlmann, P. (2020). Procedimentos e critérios para zoneamento de planícies de inundação em áreas urbanas. Revista de Gestão de Água da América Latina, 17, e13. https://doi.org/10.21168/rega.v17e13

\begin{abstract}
RESUMO: O zoneamento de áreas de risco de inundação é uma medida não-estrutural que permite reduzir os impactos de cheias fluviais através do disciplinamento do uso do solo. A implementação desta ferramenta de planejamento urbano ocorre em muitos países da Europa e, principalmente, no Estados Unidos, mas é insipiente no Brasil. Este artigo tem o objetivo de fornecer subsídios para a consolidação de critérios técnicos e procedimentos de análise na implementação de zoneamento de planícies de inundação no Brasil. A metodologia proposta contempla não apenas a simulação hidráulica, mas também aspectos de mapeamento e ordenamento do uso do solo em função do risco de inundação. De modo a ilustrar a aplicação da metodologia e permitir a visualização de dificuldades de ordem prática, o zoneamento da planície de inundação foi aplicado ao rio Caí, no município de Montenegro-RS, resultando na discussão de uma proposta de zoneamento para o município. 0 trecho do rio em análise foi subdividido em segmentos visando a uniformização de larguras e profundidades da zona de passagem da cheia em cada município. A análise de sensibilidade do parâmetro de máxima sobre-elevação da linha d'água levou a conclusão de que tal parâmetro tem impacto significativo na largura da zona de passagem da cheia. Com base no plano diretor do município de Montenegro, foi realizada análise de adequação dos usos e atividades na zona de passagem da cheia e na zona de risco de inundação. Verificou-se significativa ocupação urbana na zona de passagem da cheia (cerca de 35\% na margem da cidade de Montenegro), o que acarretou a proposta de uma classe específica do zoneamento, de zona de passagem da cheia com ocupação consolidada. As discussões e análises realizadas têm potencial para subsidiar a elaboração de um guia técnico que permita a incorporação do estudo de hidráulica à prática da gestão do território urbano dos municípios e a disseminação da ferramenta de zoneamento no Brasil.
\end{abstract}

Palavras-chave: Gestão de Risco; Inundações; Zona de Passagem da Cheia; Zoneamento de Uso do Solo; Planejamento Urbano.

ABSTRACT: Floodplain zoning is a non-structural measure that can lead to the reduction of floodplain impacts through land use regulation. This planning tool is utilized in many European countries and, especially, in the United States, however it is incipient in Brazil. The goal of this paper is to provide a contribution to strengthen the floodplain zoning in Brazil. The proposed methodology encompasses both hydraulic and land use regulation aspects regarding flooding risk. The Caí river case in Montenegro city is presented to illustrate the methodology application and to demonstrate the practical difficulties faced during the development of floodplain regulations, resulting in a discussion for Montenegro's zoning proposal. The river reach under study was segmented aiming to make the floodway depth and width uniform in each city. The sensitivity analysis performed for the maximum allowable rise on flood elevation led to the conclusion that such parameter has strong impact on floodway width. Considering the floodplain zoning, an analysis of adequacy of the land use established by Montenegro city's urban plan was carried out. A significant urban occupation in the floodway zone was observed in Montenegro (approx. 35\%), leading to a specific type of floodway zone in which construction is allowed under restriction. The performed analyses and discussions can potentially be applied to support the development of a technical guide aimed to incorporate hydraulic studies into land use planning and to disseminate floodplain regulation tools in Brazil.

Keywords: Risk Management; Flooding; Floodway; Land Use Regulation; Urban Planning.

Recebido: Abril 03, 2020. Revisado: Maio 26, 2020. Aceito: Julho 22, 2020. 


\section{INTRODUÇÃO}

A inundação ribeirinha é um processo natural, em que os rios de planície extravasam sua calha menor nos períodos chuvosos e inundam a calha maior, ou áreas ribeirinhas. Quando a população ocupa as áreas ribeirinhas, o que ocorre normalmente em anos mais secos, em que não há o extravasamento do rio, a inundação impõe riscos à vida e ao patrimônio. 0 crescimento das áreas urbanas, a intervenção humana nos rios e as mudanças climáticas têm aumentado a frequência e a severidade dos eventos de inundação nas últimas décadas (Green et al., 2000; Bronstert, 2003; Sole et al., 2008; Kourgialas \& Karatzas, 2011; Barendrecht et al., 2017).

A gestão de áreas de risco de inundação envolve medidas estruturais, que são obras de proteção ou de aumento da capacidade de escoamento da cheia, e não-estruturais, voltadas para mitigação de riscos e prevenção do agravamento dos prejuízos com inundações. As medidas não-estruturais contemplam o disciplinamento do uso do solo em áreas de risco de inundação, visando reduzir os impactos por meio de uma melhor convivência da cidade com o risco. Medidas não-estruturais não resolvem problemas consolidados, mas permitem reduzir o agravamento da situação no futuro. Políticas baseadas nestas medidas, desenvolvida nos Estados Unidos (EUA) e depois na Europa, desde os anos 70 tem norteado a de gestão de inundações ribeirinhas em vários países (Tucci, 2007), como na Inglaterra (United Kingdom Environment Agency, 2016), na Suíça (Surminski \& Eldridge, 2014), na França (Driee, 2020), na Alemanha (Länder-Arbeitsgemeinschaft Wasser, 2006) e no Canadá (Murray, 2017; Natural Resources Canada, 2018).

No Brasil, uma iniciativa do governo federal permitiu a elaboração de um atlas com o mapeamento de vulnerabilidade de áreas suscetíveis a inundações e deslizamentos em todo o país, para fins de planejamento estratégico (Agência Nacional de Águas, 2014). A escala da informação (1:1.000.000), no entanto, não permite planejar o uso do solo em escala urbana. Também de amplitude nacional, o Serviço Geológico do Brasil (2020) produziu cartas de suscetibilidade a movimentos gravitacionais de massa e inundações em 510 município brasileiros. As cartas indicam de modo qualitativo, em escalas maiores que 1:100.000, áreas de maior ou menor suscetibilidade aos processos representados. Também no meio acadêmico existe uma profusão de estudos hidrológicos e de mapeamento de inundações em áreas urbanas, alguns dos quais citados no item 2.1. No entanto, ressalta-se a insipiência de aplicações voltadas para o disciplinamento do uso do solo, analisando o que pode ser adequado no ordenamento territorial em função dos riscos de inundação. Por consequência, falta integração das estratégias de gestão de risco de inundações amplamente estudadas e descritas no meio técnico e acadêmico, com a prática da gestão do uso do solo urbano nas cidades brasileiras, expressa pelos Planos Diretores Municipais (PDM). Os municípios com uso do solo disciplinado em áreas inundáveis no Brasil são poucos. Tucci (2007) menciona Estrela - RS, que incorporou cotas de cheia do rio Taquari-Antas ao seu plano diretor, em 1983. Righi (2016) destaca que, "no Brasil, são raros os trabalhos que utilizam em suas metodologias modelos hidrológicos e hidráulicos para definir tempos de retorno (TR) de inundações graduais, bem como sua análise integrada com a distribuição da população e suas condições sociais". Como consequência, há uma grande carência por iniciativas de mapeamento e zoneamento de planícies de inundação no país.

Os maiores esforços para consolidar uma legislação de gestão de risco de desastres naturais no Brasil iniciaram apenas em 2011, após a tragédia da região serrana do Rio de Janeiro ${ }^{1}$, com a implementação da Lei Federal (LF) n ${ }^{\circ} 12.608 / 2012$, a qual instituiu a Política Nacional e o Sistema Nacional de Proteção e Defesa Civil. A referida lei atribui aos municípios, entre outras competências, "identificar e mapear as áreas de risco de desastres" e "promover a fiscalização das áreas de risco de desastre e vedar novas ocupações nessas áreas". A mesma LF ainda determina que, aqueles municípios incluídos em cadastro nacional de área suscetíveis a deslizamentos e inundações deverão elaborar o mapeamento de tais áreas, planos de contingências, entre outras medidas. As disposições da LF $\mathrm{n}^{\circ} 12.608 / 2012$ definem o papel do município para atendimento ao que estabelece a Lei de Parcelamento do Solo Urbano (LF n ${ }^{\circ} 6766 / 1979$ ), que não será permitido o parcelamento do solo em terrenos alagadiços e sujeitos a inundações, antes de tomadas as providências para assegurar $o$ escoamento das águas. No entanto, visto que a ocupação urbana está intimamente ligada aos cursos d'água e, não raro, as cidades desenvolvem-se no entorno de rios, importa aprofundar a discussão

\footnotetext{
${ }^{1}$ Eventos de chuvas torrenciais ocasionaram o deslizamento de encostas e enxurradas em córregos de áreas rurais com grande ocupação urbana, principalmente nas cidades de Nova Friburgo, Petrópolis e Teresópolis, no estado do Rio de Janeiro, resultando na morte de mais de 1000 pessoas e em outros milhares de desabrigados.
} 
técnica sobre quais são as citadas "providências para assegurar o escoamento das águas" e de que maneira isso pode ser regulamentado de forma segura e factível.

O objetivo deste trabalho é fornecer subsídios para a sistematização de procedimentos e para a consolidação de critérios técnicos na implementação de zoneamento de planícies de inundação no Brasil. Para tal, nos itens a seguir são discutidos conceitos, critérios e procedimentos de mapeamento e zoneamento de áreas inundáveis, que subsidiaram uma proposta metodológica, apresentada no item 2. De modo a ilustrar dificuldades e aspectos práticos da elaboração do zoneamento da planície de inundação, a metodologia é aplicada à cidade de Montenegro-RS, em um trecho do rio Caí, cujos resultados são discutidos no item 3 .

\subsection{Mapeamento de áreas inundáveis e zoneamento da planície de inundação}

O zoneamento da planície de inundação tem diferentes abordagens em diferentes países, mas, de forma geral, parte do mapeamento de áreas inundáveis. Os mapas podem ser gerados com base em cotas conhecidas de inundação na região ou com base em cheias de projeto, associadas a tempos de retorno. A partir dos mapas de limite da inundação, a área de restrição a ocupação pode ser determinada simplesmente pela consideração de uma cota segura, ou através da delimitação de uma zona de passagem da cheia. Este item discute estas abordagens e descreve as diferentes análises sobre mapas de áreas inundáveis que conduzem ao conceito de zoneamento de planície de inundação.

0 mapeamento de áreas inundáveis, ou de perigo de inundação, permite a visualização das áreas sujeitas a inundação no espaço e consiste basicamente em representar a linha d'água de cheia em planta (mapa), cruzando a informação de altura da lâmina d'água com a topografia do terreno. As informações de profundidade e de velocidade do fluxo d'água podem ser utilizadas em conjunto com a área inundável, agregando informação para a interpretação de potencial de causar danos de uma determinada cheia. Os mapas de áreas inundáveis podem ser utilizados no nível de planejamento regional, para definição de ações de prevenção e proteção contra cheias e, no nível operacional, para planejamento urbano (ordenamento do uso do solo), sistema de seguro contra inundações ou como parte de um sistema de monitoramento e alerta de cheias.

Há estudos em que os níveis de inundação são estimados com base em cotas conhecidas de eventos de cheia ou mesmo em curvas de nível de elevação do terreno (hipsometria), como em Cavalcanti et al. (2013), Leite \& Rocha (2016), Rezende \& Marques (2017), Ferreira (2019) e Menegasso (2019). Em tais estudos, a declividade da linha d'água não é representada de acordo com o fluxo do rio. Tais métodos, que não utilizam simulação hidráulica para estimativa da cota de cheia, são mais adequados para mapeamento de remansos e estuários, em que a declividade da linha d'água é insignificante. Ainda, quando as cotas de cheias não estão vinculadas a uma probabilidade de ocorrência (ou tempo de retorno), o uso dos mapas fica limitado, pois o método não permite o cálculo do risco.

Para incorporar a probabilidade de ocorrência dos eventos de cheia, é necessário estudo hidrológico, e para a representação da linha d'água, é necessária a realização de estudo hidráulico do rio, como em Hora \& Gomes (2009), Silva et al. (2016), Righi (2016). 0 estudo hidráulico é executado com base em informações de vazão e de configuração da calha do rio e da planície de inundação. A vazão de projeto é obtida de estudo hidrológico, em que, através do ajuste estatístico de valores de vazão máxima da série histórica, é definida a probabilidade de ocorrência e o tempo de retorno do evento de cheia de projeto. A representação do trecho de rio é obtida por meio de levantamentos topobatimétricos, topográficos e cadastrais. A topobatimetria do rio e o cadastro de obstruções permitem a representação da calha e, a planialtimetria, a caracterização da planície de inundação.

O mapeamento de áreas inundáveis, quando associado a informações de danos potenciais ou vulnerabilidade, conduz aos mapas de risco de inundação. 0 risco é calculado relacionando o dano potencial (referente à ocupação do território) com a probabilidade de ocorrência (referente ao evento de cheia), como em Silva et al. (2016) e Righi (2016), ou com a cota provável da inundação (quando não há estudo hidráulico), como em Ferreira (2019) e Menegasso (2019). Tais mapas retratam os riscos da situação atual de ocupação da planície de inundação, destacando, em função dos maiores riscos, as áreas com alta frequência de inundação e com maiores danos potenciais (ocupação). Este diagnóstico é de grande interesse e serve como subsídio para análise de viabilidade na implementação de planos de alerta de cheia, de seguros contra inundação e de obras de proteção. Para o planejamento do solo urbano, no entanto, importa a definição das atividades e usos do solo que serão permitidos em área de risco no futuro. Neste caso, o foco da análise passa a ser as áreas inundáveis que ainda não 
foram ocupadas ou não estão consolidadas, em que o poder público pode atuar de forma preventiva através do ordenamento do uso do solo.

O mapeamento de áreas inundáveis, quando associado a regras de disciplinamento do uso do solo, passa a se denominar zoneamento de áreas inundáveis, ou Zoneamento da Planície de Inundação (ZPI). Entende-se por ZPI, a determinação das características da cheia em diferentes regiões da planície de inundação e, baseado nestas características, a regulação do uso do solo na região. Nos EUA, onde esta ferramenta de planejamento é largamente utilizada para subsidiar o sistema nacional de seguros e o ordenamento do território das planícies de inundação (Federal Emergency Management Agency, 2019), o ZPI foi definido ainda na década de 70 como "a regulamentação do: (1) uso das estruturas e do solo; (2) tamanho e volume das estruturas; e (3) o tamanho dos lotes e a densidade de uso" (Water Resources Council, 1971). A divisão do território em zonas permite uma análise mais detalhada das características de cada área, e possivelmente, possibilita maior controle sobre a forma urbana planejada.

Seguindo esse conceito, a planície de inundação é dividida em três regiões básicas, as quais possuem características hidráulicas e recomendações de ocupação próprias (Figura 1): (1) Zona de Passagem da Cheia (ZPC) é a zona que possui função hidráulica e é responsável pelo escoamento da cheia propriamente dita, com altas velocidades e maiores profundidades. É proibida a ocupação que ocasione elevação na linha d'água de cheia; (2) Zona de Risco de Inundação (ZRI) é a zona adjacente à ZPC, na qual o escoamento é mais lento e menos profundo, mas ainda pode gerar dano. É possível a ocupação, desde que tomadas providências para prevenção de inundações; (3) Zona de Baixo Risco (ZBR) é a zona localizada fora da área de inundação para o tempo de retorno estabelecido como base e não necessita de regulamentação específica para proteção contra inundações ribeirinhas. Cabe aqui ressaltar que, o fato de o risco de inundação ribeirinha ser baixo nestas áreas, não as isenta de sofrerem inundações devido a deficiências na drenagem pluvial local, o que deve ser tratado nos projetos de engenharia de cada empreendimento.

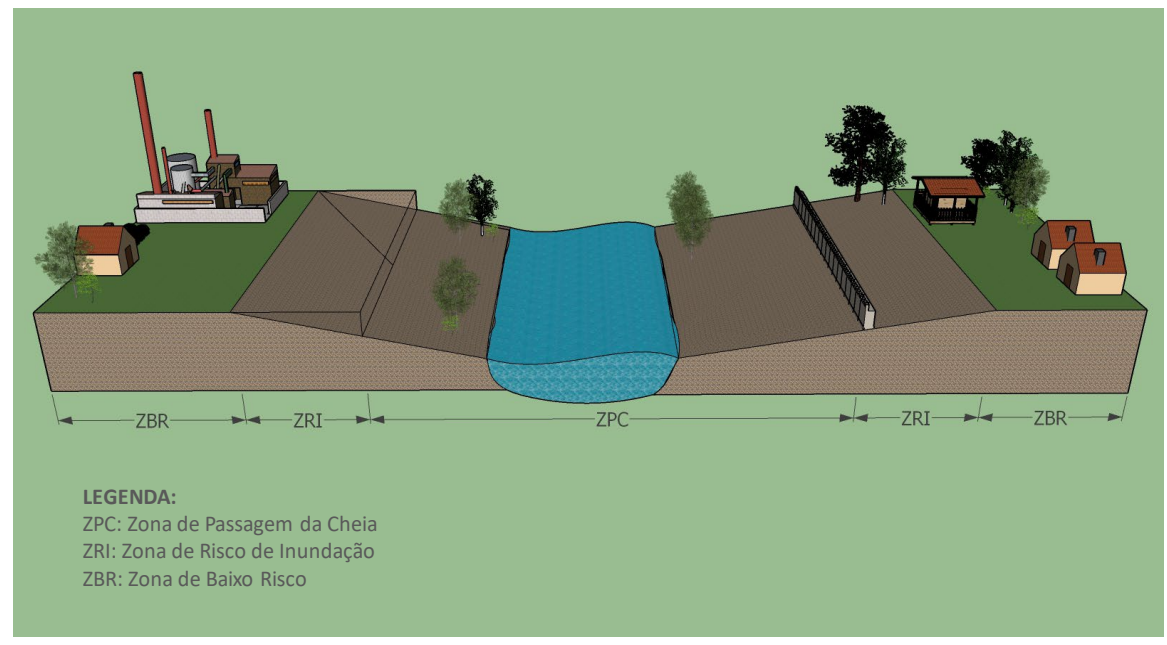

Figura 1. Zoneamento da planície de inundação

O conceito geral de ZPI descrito acima, no entanto, apresenta uma variedade de metodologias e formas de aplicação em diferentes países e localidades. A Tabela 1 apresenta os tipos de mapas e os diferentes critérios de análise de países, estados e cidades que desenvolveram instrumentos de mapeamento e zoneamento de inundação. Além dos tipos de mapa, local de aplicação e fonte da informação, a Tabela 1 traz informação de:

- $\quad$ Finalidade: quanto a aplicação do mapa, para diagnóstico, sistema de seguros, sistema de alerta, projetos de obras de proteção, ordenamento territorial, ou outras; o diagnóstico é a etapa inicial de planejamento, subsídio para ações futuras e inclui, nesta classificação, mapas gerados apenas para conhecimento público;

- Variáveis: informações utilizadas na composição dos mapas, de acordo com sua finalidade;

- Tempo de retorno: probabilidade de ocorrência da cheia, que define os limites da área inundada; 
- Simulação hidráulica: se foi ou não utilizado algum modelo computacional de simulação hidráulica para cálculo dos níveis d'água de cheia. Caso não, os níveis foram estimados através de cotas de cheia conhecidas na região do estudo;

- $\quad$ ZPC: se foi ou não delimitada a zona de passagem da cheia.

Tabela 1. Tipos de mapas de inundação, aplicações e critérios de elaboração

\begin{tabular}{|c|c|c|c|c|c|c|c|}
\hline Tipo de mapa & Local & Finalidade & Variáveis & $\begin{array}{l}\text { Tempo } \\
\text { de } \\
\text { retorno } \\
\text { (anos) }\end{array}$ & $\begin{array}{l}\text { Simulação } \\
\text { hidráulica }\end{array}$ & ZPC & Fonte \\
\hline \multirow{11}{*}{$\begin{array}{l}\text { Mapas de áreas } \\
\text { inundáveis } \\
\text { (podem trazer, } \\
\text { além da } \\
\text { informação de } \\
\text { área inundável, } \\
\text { profundidade } \\
\text { da lâmina } \\
\text { d’água, } \\
\text { velocidade do } \\
\text { fluxo e material } \\
\text { sólido carreado } \\
\text { na cheia) }\end{array}$} & $\begin{array}{c}\text { Bade- } \\
\text { Vurtemberga, } \\
\text { Alemanha }\end{array}$ & Diagnóstico & $\begin{array}{c}\text { Área e } \\
\text { profundidade }\end{array}$ & $\begin{array}{l}100 \mathrm{e} \\
1000\end{array}$ & Sim & Não & $\begin{array}{c}\text { Länder- } \\
\text { Arbeitsgemeinschaft } \\
\text { Wasser (2006) }\end{array}$ \\
\hline & $\begin{array}{l}\text { Renânia do } \\
\text { Norte- } \\
\text { Vestfália, } \\
\text { Alemanha }\end{array}$ & Diagnóstico & $\begin{array}{c}\text { Área, } \\
\text { profundidade e } \\
\text { velocidade }\end{array}$ & $\begin{array}{c}10,50 \\
100 \text { e } 300\end{array}$ & Sim & Não & $\begin{array}{c}\text { Länder- } \\
\text { Arbeitsgemeinschaft } \\
\text { Wasser (2006) }\end{array}$ \\
\hline & $\begin{array}{l}\text { Saxônia, } \\
\text { Alemanha }\end{array}$ & Diagnóstico & $\begin{array}{c}\text { Área e } \\
\text { profundidade }\end{array}$ & $\begin{array}{c}20,50 \\
100,200 \\
300 \text { e } 500\end{array}$ & Sim & Não & $\begin{array}{c}\text { Länder- } \\
\text { Arbeitsgemeinschaft } \\
\text { Wasser }(2006)\end{array}$ \\
\hline & $\begin{array}{l}\text { França } \\
\text { (algumas } \\
\text { regiões) }\end{array}$ & Diagnóstico & Área & 100 & Sim & Não & Eximap (2007) \\
\hline & $\begin{array}{c}\text { Norte- } \\
\text { Estreito de } \\
\text { Calé, França }\end{array}$ & Diagnóstico & $\begin{array}{c}\text { Área e } \\
\text { profundidade }\end{array}$ & $\begin{array}{l}10 \text { e } 100 \text { e } \\
\text { eventos }^{1}\end{array}$ & Sim & Não & Eximap (2007) \\
\hline & Inglaterra & $\begin{array}{c}\text { Seguros e } \\
\text { diagnóstico }\end{array}$ & Área & $\begin{array}{l}100 \mathrm{e} \\
1000\end{array}$ & $\begin{array}{c}\text { Não } \\
\text { informado }\end{array}$ & Não & $\begin{array}{l}\text { Ministry of Housing } \\
\text { Communities \& } \\
\text { Local Government } \\
(2014)\end{array}$ \\
\hline & $\begin{array}{l}\text { Alberta, } \\
\text { Canadá }\end{array}$ & Diagnóstico & Área & 100 & Sim & Sim & $\begin{array}{c}\text { Alberta Waterportal } \\
\text { Society (2017) }\end{array}$ \\
\hline & $\begin{array}{l}\text { Columbia } \\
\text { Britânica, } \\
\text { Canadá }\end{array}$ & $\begin{array}{l}\text { Sistemas de } \\
\text { alerta e } \\
\text { diagnóstico }\end{array}$ & Área & 200 & Sim & Não & $\begin{array}{c}\text { Government Of } \\
\text { British Columbia } \\
\text { (2020) }\end{array}$ \\
\hline & $\begin{array}{l}\text { Rio dos Sinos } \\
- \text { RS }\end{array}$ & $\begin{array}{l}\text { Projetos de } \\
\text { proteção }\end{array}$ & $\begin{array}{c}\text { Área, } \\
\text { profundidade e } \\
\text { velocidade }\end{array}$ & 100 & Sim & $\mathrm{Sim}^{2}$ & Metroplan (2018a) \\
\hline & $\begin{array}{c}\text { Rio Gravataí - } \\
\text { RS }\end{array}$ & $\begin{array}{l}\text { Projetos de } \\
\text { proteção }\end{array}$ & $\begin{array}{c}\text { Área, } \\
\text { profundidade e } \\
\text { velocidade }\end{array}$ & 100 & Sim & $\mathrm{Sim}^{2}$ & Metroplan (2018b) \\
\hline & $\begin{array}{l}\text { Brasil (510 } \\
\text { municípios) }\end{array}$ & Diagnóstico & Área & $\begin{array}{l}\text { Não se } \\
\text { aplica }^{3}\end{array}$ & & & $\begin{array}{l}\text { Serviço Geológico } \\
\text { do Brasil (2020) }\end{array}$ \\
\hline \multirow{2}{*}{$\begin{array}{c}\text { Mapas de risco } \\
\text { (áreas } \\
\text { inundáveis X } \\
\text { vulnerabilidade } \\
\text { da ocupação } \\
\text { urbana) } \\
\end{array}$} & Brasil & Diagnóstico & Não informado & $\begin{array}{l}\text { Não se } \\
\text { aplica }^{4}\end{array}$ & Não & Não & $\begin{array}{l}\text { Agência Nacional de } \\
\text { Águas (2014) }\end{array}$ \\
\hline & $\begin{array}{l}\text { Renânia- } \\
\text { Palatinado, } \\
\text { Alemanha }\end{array}$ & Diagnóstico & Não informado & $\begin{array}{l}50,100 \\
200 \mathrm{e} \\
\text { maiores }\end{array}$ & Sim & Não & $\begin{array}{c}\text { Länder- } \\
\text { Arbeitsgemeinschaft } \\
\text { Wasser (2006) }\end{array}$ \\
\hline \multirow{4}{*}{$\begin{array}{l}\text { Zoneamento da } \\
\text { planície de } \\
\text { inundação } \\
\text { (mapas de áreas } \\
\text { inundáveis com } \\
\text { orientações de } \\
\text { ocupação do } \\
\text { solo urbano por } \\
\text { zona) }\end{array}$} & $\begin{array}{l}\text { Estados } \\
\text { Unidos }\end{array}$ & $\begin{array}{c}\text { Seguros e } \\
\text { ordenamento } \\
\text { territorial }\end{array}$ & $\begin{array}{c}\text { ZPI, usos } \\
\text { permitidos e } \\
\text { padrões } \\
\text { construtivos }\end{array}$ & 100 & Sim & Sim & $\begin{array}{c}\text { Federal Emergency } \\
\text { Management } \\
\text { Agency (2019) }\end{array}$ \\
\hline & $\begin{array}{l}\text { Manitoba, } \\
\text { Canadá }\end{array}$ & $\begin{array}{l}\text { Ordenamento } \\
\text { territorial }\end{array}$ & $\begin{array}{l}\text { Profundidade } \\
\text { de } 1 \mathrm{~m} \text { define } \\
\text { ZPC }\end{array}$ & $\begin{array}{c}100 \mathrm{e} \\
\text { evento }^{1}\end{array}$ & Sim & Sim & Murray (2017) \\
\hline & $\begin{array}{l}\text { Nova Escócia } \\
\text { e Quebec, } \\
\text { Canadá }\end{array}$ & $\begin{array}{l}\text { Ordenamento } \\
\text { territorial }\end{array}$ & $\begin{array}{c}\text { Alta velocidade } \\
\text { do fluxo abaixo } \\
\text { de } 20 \text { anos de } \\
\text { tempo de } \\
\text { retorno } \\
\end{array}$ & 20 e 100 & Sim & $\operatorname{Sim}$ & Murray (2017) \\
\hline & $\begin{array}{l}\text { Calgary - } \\
\text { Alberta, } \\
\text { Canadá }\end{array}$ & $\begin{array}{l}\text { Ordenamento } \\
\text { territorial }\end{array}$ & $\begin{array}{l}\text { Usos permitidos } \\
\text { e padrões } \\
\text { construtivos }\end{array}$ & 100 & Sim & Sim & $\begin{array}{l}\text { City of Calgary } \\
\text { (2020) }\end{array}$ \\
\hline
\end{tabular}




\begin{tabular}{|c|c|c|c|c|c|c|c|}
\hline Tipo de mapa & Local & Finalidade & Variáveis & $\begin{array}{l}\text { Tempo } \\
\text { de } \\
\text { retorno } \\
\text { (anos) }\end{array}$ & $\begin{array}{l}\text { Simulação } \\
\text { hidráulica }\end{array}$ & ZPC & Fonte \\
\hline & $\begin{array}{l}\text { Columbia } \\
\text { Britânica, } \\
\text { Canadá }\end{array}$ & $\begin{array}{l}\text { Ordenamento } \\
\text { territorial }\end{array}$ & $\begin{array}{c}\text { Distância da } \\
\text { margem, cota e } \\
\text { padrão } \\
\text { construtivo }\end{array}$ & 200 & Sim & Sim & $\begin{array}{l}\text { Government of } \\
\text { British Columbia } \\
\text { (2020) }\end{array}$ \\
\hline & $\begin{array}{l}\text { Rio dos Sinos } \\
\text { / Taquara-RS }\end{array}$ & $\begin{array}{l}\text { Ordenamento } \\
\text { territorial }\end{array}$ & $\begin{array}{l}\text { Zoneamento } \\
\text { urbano e } \\
\text { atividades } \\
\text { permitidas }\end{array}$ & 100 & Sim & Sim & $\begin{array}{l}\text { Prefeitura Municipal } \\
\text { de Taquara }(2018)^{2}\end{array}$ \\
\hline
\end{tabular}

1 Baseado em cotas de cheias conhecidas nas cidades. 2 Proposto nos estudos, mas não implementado. 3 Analisados trechos de rio (linhas) e não áreas inundáveis (polígonos). 4 Limites de inundação baseados em aspectos topológicos e geomorfológicos, não em estudo hidrológico/hidráulico.

\subsection{Critérios hidrológicos do zoneamento da planície de inundação}

A definição de qual é a Zona de Risco de Inundação (ZRI), conforme conceito da Figura 1, depende da definição de qual é a cheia de projeto, ou seja, qual o tempo de retorno a ser considerado. Nos Estados Unidos, a cheia de projeto utilizada no sistema de seguros contra cheia (base flood) é de 100 anos de tempo de retorno (Federal Emergency Management Agency, 2019). Em diferentes países, o tempo de retorno adotado para definição de áreas de risco de inundação variam de 30 a 1000 anos (Federal Emergency Management Agency, 2019, United Kingdom Environment Agency, 2016, Surminski \& Eldridge, 2014).

Uma vez definida a cheia de projeto, que delimita a ZRI, a análise passa à subdivisão desta zona para fins de ordenamento do uso do solo. É nesta análise em que há duas abordagens básicas para o problema: uma, de forma geral, aplicada na Europa e outra, nos Estados Unidos.

Conforme se verifica na Tabela 1, a experiência europeia, também utilizada na maior parte do Canadá, se baseia na produção de mapas de áreas inundáveis com faixas de terreno definidas entre limites de inundação de cheias de diferentes tempos de retorno e critérios de perigo, como profundidade e velocidade do fluxo. Não há a definição de limites físicos de uma zona de passagem da cheia, mas apenas a determinação de faixas com maior ou menor probabilidade de inundação, em função do tempo de retorno ou altura da lâmina d'água. Tais mapas, utilizados como subsídio para ordenamento territorial em planícies de inundação, não contemplam os efeitos da ocupação futura sobre a elevação da linha d'água de cheia a montante.

Neste sentido, os Estados Unidos e a província de Alberta, no Canadá, consideram um critério a mais para o zoneamento: a Máxima Sobre-elevação Admissível (MSEA) da linha d'água de cheia, conforme descrito em Federal Emergency Management Agency (2019) e Alberta Waterportal Society (2017), respectivamente. Este critério agrega à análise de zoneamento da planície de inundação uma variável que representa o impacto admitido (sobre-elevação) na lâmina d'água de cheia a montante e permite incorporar no planejamento o efeito da ocupação sobre o nível da cheia no futuro. A grande diferença das demais aplicações ilustradas é que, no processo de delimitação da zona de passagem da cheia, a geometria da calha do rio no modelo hidráulico é ajustada, elevando-se a cota do terreno no limite da ZPC, de modo a representar uma futura ocupação na faixa adjacente a zona de passagem da cheia. É essa consideração que torna a aplicação dos mapas de áreas inundáveis especialmente apropriada para o planejamento do uso do solo urbano, em que não se ignora os impactos da ocupação urbana prevista no plano diretor sobre as áreas de baixo risco de inundação.

Nos Estados Unidos, a máxima sobre-elevação admitida da linha d'água, que seria gerada por uma ocupação do solo hipotética, é de 1 pé, ou seja, aproximadamente $30 \mathrm{~cm}$ (Federal Emergency Management Agency, 2019). Não há uma justificativa técnica de qual deve ser a elevação da linha d'água adotada, entretanto, caso nenhuma elevação na linha d'água fosse permitida, praticamente nenhum desenvolvimento poderia ocorrer na região e, por outro lado, se elevações maiores fossem permitidas, os prejuízos oriundos de novas construções e/ou reformas poderiam ser muito significativos. De qualquer forma, os Estados podem definir critério mais restritivo (sobre-elevação menor) (Federal Emergency Management Agency, 2019). Este critério permitiu aos EUA adequar o zoneamento ao seu processo de urbanização, que, diferentemente da Europa, ainda era dinâmico quando o sistema de seguros foi instituído, na década de 1960.

No Brasil, não há uma norma e nem sequer uma praxe para a definição dos principais critérios hidrológicos para delimitação da ZPC. Conforme discutido no item 1.1, as iniciativas seguem, em geral, 
a abordagem europeia, com a delimitação de faixas de inundação para diferentes tempos de retorno, retratando o que ocorreria em caso de cheia na situação atual de ocupação do solo, no âmbito de diagnóstico.

\subsection{0 uso do HEC-RAS para delimitação da zona de passagem da cheia}

O HEC-RAS é um modelo de simulação hidráulica muito usado para estudos de delimitação de áreas de inundação (Beavers, 19942, apud Tate \& Maidment, 1999; Tate \& Maidment, 1999; Earles et al., 2004; Nut \& Plermkamon, 2015; Patel \& Gundaliya, 2016; Demir \& Kisi, 2016). Ele pode ser utilizado em regime permanente ou não-permanente para a delimitação de uma cheia na calha natural ou ainda, em regime permanente, para a delimitação da ZPC. Para este último caso, o HEC-RAS oferece uma ferramenta específica de simulação de obstrução da calha (encroachments), representando obras como diques e aterros. Esta ferramenta possibilita a análise da influência da obstrução do fluxo na margem (representando a ocupação do solo), observando tanto a largura quanto a elevação da linha d'água em cada seção transversal (United States Army Corps of Engineers, 2016). A Figura 2 apresenta um diagrama simplificado de uma seção transversal de um curso d'água, mostrando a elevação da linha d'água antes e após a adição dos encroachments na mesma. O HEC-RAS disponibiliza cinco métodos diferentes para a realização desta análise, são eles (United States Army Corps of Engineers, 2016):

- Método 1: o usuário pode especificar os limites da área a ser utilizada para a passagem da cheia, para as margens direita e esquerda, em cada seção transversal;

- Método 2: o usuário pode especificar a largura máxima que a área de inundação pode apresentar, sem definir os limites nos lados esquerdo e direito;

- Método 3: o usuário determina a porcentagem de redução da capacidade de transporte do canal (conveyance);

- Método 4: o usuário especifica a elevação máxima do nível d'água que pode ocorrer em uma determinada área de passagem de cheia;

- Método 5: o usuário especifica a elevação máxima do nível d'água e a elevação máxima do nível de energia que podem ocorrer em uma determinada área de passagem de cheia, controlando assim o aumento da velocidade nas seções.

Para a determinação da zona de passagem de cheia, a condição de encroachments deve ser aplicada de jusante para montante observando-se a elevação da linha d'água resultante. 0 procedimento pode ser realizado de diversas maneiras, combinando mais de um método de análise para obtenção de um resultado mais preciso. Os desenvolvedores sugerem, por exemplo, ajustar valores iniciais através dos Métodos 4 ou 5 e aprimorar os resultados através do Método 1 (United States Army Corps of Engineers, 2016), mas outras combinações também podem ser utilizadas.

Os resultados da ferramenta informam qual seria a elevação da linha d'água caso a área dos encroachments apresente alteração na ocupação do solo. O HEC-RAS permite a visualização dos resultados tanto na forma tabular, quanto na forma gráfica. Devido às condições topográficas, diferentes em cada seção transversal, a elevação da linha d'água pode não alcançar seu valor máximo em todas as seções (Federal Emergency Management Agency, 2019), desta maneira, deve-se verificar a cada tentativa se a elevação máxima permitida foi atingida em alguma das seções transversais em estudo.

\footnotetext{
2 Beavers, M.A. (1994). Floodplain Determination Using HEC-2 and Geographic Information Systems. Dissertação de Mestrado em Engenharia Civil, 389f. The University of Texas at Austin.
} 


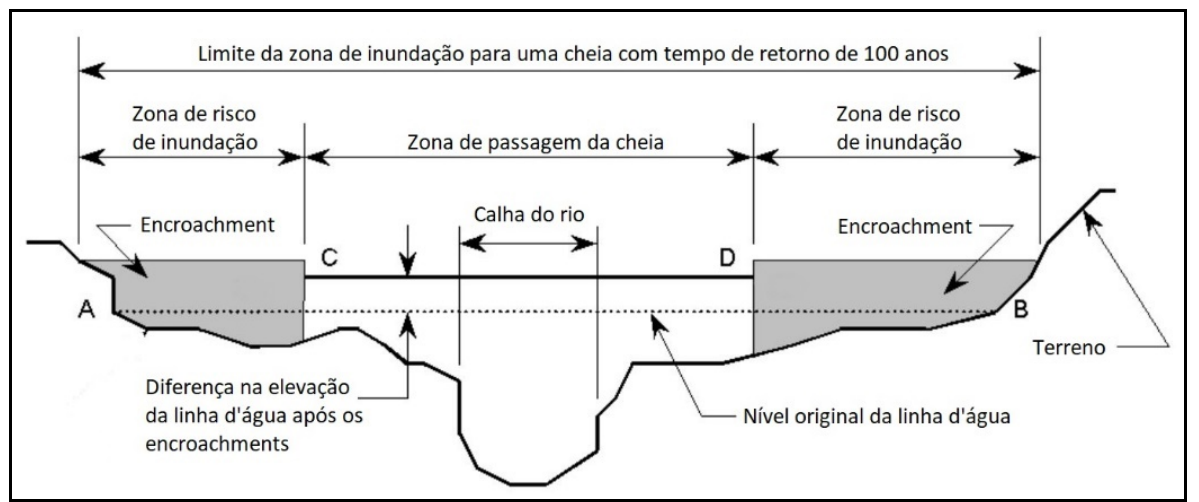

Figura 2. Seção transversal de um rio em análise quanto a questão da zona de passagem de cheia (Adaptado de Missouri Department of Transportation, 2019).

\subsection{Implicações na definição do zoneamento da planície de inundação}

Não é apenas a definição de critérios hidrológicos que permitem a concretização do ZPI. A ocupação do solo e a presença de áreas já consolidadas devem ser levadas em consideração para definir o zoneamento de acordo com as particularidades locais, como percepção da comunidade, forças políticas e econômicas, crescimento populacional, entre outros.

O que se define com o ZPI, é que a ZRI pode ser ocupada, desde que tomadas as providências para proteção contra as eventuais cheias. As referidas providências, na prática, são traduzidas por meio de dois tipos de medidas estruturais: diques e aterros - e por regulações de usos, atividades e métodos construtivos resilientes à inundação. Os principais aspectos objeto de discussão com a aprovação do ZPI são:

- Efeitos de remanso: a implantação de diques ou aterros na ZRI ocasiona uma sobre-elevação na linha d'água do rio, chamado remanso, que aumenta o efeito de inundação na margem oposta e a montante. Para a definição do zoneamento, conforme Federal Emergency Management Agency (2019), este efeito de jusante para montante, que é a base de definição da zona de passagem da cheia, é obrigatoriamente considerado. No estudo de ZPI, os impactos da obra devem ser considerados, prevendo mitigação e/ou compensação. Com a aprovação do ZPI, a ZRI passará a ser progressivamente ocupada. Com os projetos de cada desenvolvimento individual respeitando os limites definidos no ZPI, não será mais necessária a avaliação caso a caso do risco de inundação ribeirinha e dos impactos a montante. 0 efeito de sobre-elevação da linha d'água aumentará até, no máximo, o limite estabelecido para a definição da largura da ZPC, quando a ZRI estiver plenamente ocupada;

- Aspectos urbanísticos: segundo Pohlmann (2016), devem ser consideradas as características paisagístico-ecológicas abrangendo aspectos associados ao saber local sobre os elementos físicos e subjetivos da paisagem local. Os aspectos físicos correspondem às especificidades relacionadas à função e à estrutura da paisagem e podem ser identificados a partir da morfologia da paisagem. Já os aspectos subjetivos dizem respeito às especificidades associadas à percepção dos moradores sobre a paisagem local. Um dos aspectos que dificultam a aprovação popular de uma obra de dique é a segmentação que ele impõe à paisagem urbana, separando física e visualmente a cidade do rio. Aterros necessitam de áreas maiores para implantação (o que normalmente não existe em cidades onde o problema de inundação ribeirinha já está consolidado), no entanto, permitem uma transição mais branda entre a área protegida e o rio;

- Aspectos políticos e institucionais: a construção de uma obra de grande porte como um dique ou um grande aterro, com impacto em um ou mais bairros e não raro em mais de um município, requer a iniciativa pública e aportes financeiros consideráveis. Não bastasse a dificuldade de articulação institucional entre a União, como financiador de tais obras e os Estados e municípios como empreendedores, há, no nível de gestão municipal, outras responsabilidades que demandam atenção diária dos gestores públicos. Conforme discutido por Robaina (2008), como os problemas de inundação são de natureza ocasional e não permanente, tais obras, em via de regra, não estão no topo da pauta de obras públicas, restando aos cidadãos que ocupam áreas de risco a solução de proteção. Esse aspecto é agravado quando não há um zoneamento definido da área de risco, situação comum no Brasil. Como consequência, não há a prevenção, que seria possível com o zoneamento, e nem a proteção através de obras públicas de porte. Ocorre que os 
cidadãos, usuários do território urbano, cotidianamente resolvem seus problemas de inundação por conta própria, cada um fazendo seu aterro ou pequeno dique de proteção, ou aumentando a canalização em seu entorno. 0 resultado, apesar de previsível, é caótico, e pode ser observado em todas as grandes cidades brasileiras, onde o poder público tem imensa dificuldade em prevenir eventos de inundação e até mesmo de entender o sistema de drenagem do município;

- Tipos de usos e atividades: com base nas atividades mencionadas em Federal Emergency Management Agency (1998), a ZRI pode ser destinada ao uso misto: comercial, industrial e residencial. Existem, no entanto, algumas atividades que devem ficar fora da área de risco ou aterradas em cota segura, como: hospitais, escolas, estações de tratamento de água, estações de tratamento de esgoto, subestações de energia, entre outras infraestruturas estratégicas ou com potencial de contaminação;

- Características das construções: segundo Tucci (2007), mesmo com a proteção por diques, deve-se evitar construções com apenas um piso na área de risco de inundação, devendo sempre o segundo piso estar fora da cota de cheia de 100 anos. Não sendo possível, deve-se aumentar o número de andares ou avaliar a remoção das unidades;

- Incentivos econômicos: incentivar o uso do solo urbano na área de risco para usos que tenham o menor impacto possível durante a inundação como uso agrícola, estacionamentos, parques e áreas de lazer, entre outros. Criar incentivos econômicos para proprietários que tiverem usos do solo sustentáveis, como a redução de impostos territoriais (Tucci, 2007).

No caso de ocupações consolidadas inseridas em áreas de risco (ZRI) ou de passagem da cheia (ZPC), estudos de alternativas, como SOP/Metroplan (Estado do Rio Grande do Sul, 2014) e Metroplan (2018a, 2018b), permitem definir qual tipo de medida possui a melhor relação benefício/custo e viabilidade financeira. Nesses estudos, considerou-se, por exemplo, além da realização de obras de proteção, a transferência da população local e a opção de convivência com as cheias, onde já se conhece a probabilidade da ocorrência de prejuízos.

\section{MATERIAIS E MÉTODOS}

A metodologia proposta para obtenção do ZPI contempla: (1)a definição da área de risco de inundação; (2) a definição de critérios de segmentação do trecho em estudo; (3) a definição da máxima sobre-elevação admissível da linha d'água e cálculo das larguras da zona de passagem da cheia (ZPC) em cada segmento; (4) a elaboração dos mapas de ZPI; e (5) a avaliação urbanística.

\subsection{Definição da área de risco de inundação}

A área de risco de inundação compreende a ZPC e a ZRI, conforme ilustrado na Figura 1. Seus limites são calculados através da simulação hidráulica do trecho com a cheia de projeto. Assim, sua obtenção, depende da definição de Tempo de Retorno (TR) da cheia de projeto.

A praxe indica TRs para dimensionamento de inúmeras obras, como bueiros, pontes e vertedouros de barragens. Para a definição do ZPI, no entanto, a estimativa de tempo de retorno da cheia é um campo ainda pouco explorado no Brasil e não há uma praxe internacional que possa ser adotada, conforme discutido anteriormente. Optou-se pela definição do TR de 100 anos, mesmo valor adotado para tal finalidade dos EUA. Esse é o TR recomendado também para projetos de pontes (Dnit, 2006) no Brasil. A adoção do TR de 100 anos significa que, as ocupações na área de risco de inundação terão, a cada ano, uma probabilidade de $1 \%$ de serem atingidas por uma cheia. É importante ressaltar que o TR utilizado para o cálculo da largura da ZPC não é necessariamente o TR que deve ser utilizado para o cálculo de obras de proteção e aterramento que irão conformar o limite da ZPC na prática. No caso de diques, por exemplo, o risco a ser assumido está diretamente ligado ao dano potencial, no caso de falha da obra (rompimento dos diques), e o TR de projeto pode ser muito maior do que 100 anos, como 1250 anos, para diques fluviais na Holanda (Eximap, 2007). No caso de aterros, a critério do projetista, a própria linha d'água do estudo de ZPI pode ser adotada, uma vez que caso o TR de 100 anos seja superado em um evento de cheia, a "falha" da obra significa apenas uma lâmina d'água sobre a cota mínima de aterramento.

Definido o TR, o modelo hidráulico deve ser ajustado e executado em regime permanente para a definição da linha d'água que limita a ZRI. 


\subsection{Definição de critérios de segmentação do trecho de estudo}

Em rios de planície, a própria definição da área de estudo pode impactar nos resultados. Ao decidir por qual extensão do rio o critério de máxima sobre-elevação da linha d'água deve ser respeitado, as simulações podem indicar cenários com zonas de passagem da cheia mais ou menos largas. Este fato decorre de que em rios com declividades muito suaves, sem variações bruscas na declividade do talvegue ou quedas d'água, como é o caso do trecho baixo do rio Caí, as restrições impostas a jusante propagam-se a montante, como esperado.

Recomenda-se que, em um estudo hidráulico para definição da ZPC, sejam realizadas simulações preliminares para que se tenha sensibilidade sobre a variação das larguras da zona de passagem da cheia, dividindo o trecho de rio simulado em segmentos. 0 objetivo da análise é maximizar a sobre-elevação máxima em cada segmento, sem que ocorram, em qualquer segmento, seções com sobre-elevação superior à máxima.

Outro critério, de ordem prática, refere-se à divisão política dos municípios. No intuito de evitar conflitos e facilitar a futura implantação do zoneamento (incorporação ao PDM), convém que a divisão de segmentos seja coincidente com a divisa de municípios e limites de bairros, evitando que em uma mesma unidade territorial (bairro ou município) ocorram duas larguras de ZPC. Este critério não se impõe a questão hidráulica, mas é motivo de atenção durante os estudos hidráulicos, pois pode evitar retrabalhos na aprovação do zoneamento junto a municipalidade.

\subsection{Definição dos critérios de cálculo da Máxima Sobre-Elevação Admissível da linha d'água (MSEA) e da largura da zona de passagem da cheia em cada segmento}

Como o próprio nome define, o MSEA é a máxima elevação que é admitida em um trecho de rio ao se restringir o escoamento da cheia de projeto a uma determinada largura, equivalente a ZPC. Este talvez seja o critério com maior dificuldade para definição, tanto por falta de sensibilidade sobre os resultados, quanto por falta de estudos antecedentes que pudessem servir de base. De modo a se adquirir alguma sensibilidade sobre o parâmetro, optou-se, neste estudo, por testar três valores de MSEA: 0,15, 0,35 e 0,55 m, por serem valores em torno do padrão americano, de 1 pé. Este parâmetro pode assumir diferentes valores de acordo com cada caso estudado, dependendo do impacto verificado a montante, sendo assim uma condição de contorno.

Para um determinado valor de MSEA, são executados os seguintes passos:

- $\quad$ Executar o HEC-RAS utilizando o Método 4, no qual define-se um valor para MSEA e observa-se a largura da ZPC resultante. Esse método permite a obtenção de estimativas iniciais para a largura da ZPC em cada segmento;

- A partir destes valores iniciais de ZPC, executar o HEC-RAS utilizando o Método 2, onde a largura da zona de passagem de cheia em cada seção é fixa. Para cada um dos segmentos, com valores constantes de largura da ZPC, verifica-se se a sobre-elevação da lâmina d'água permanece dentro do limite máximo (MSEA);

- Caso nenhuma seção transversal do trecho total atinja a MSEA, a largura do segmento é reduzida e vice-versa, buscando minimizar a largura da ZPC em todos os segmentos. Diversas combinações de largura entre segmentos são testadas, buscando as menores larguras possíveis para ZPC em cada um dos segmentos. Este procedimento é realizado por segmento, modificando em $+0,1 \mathrm{~km}$ a largura da ZPC, considerando dois algarismos significativos, e mantendo os segmentos restantes com o valor original até que alguma seção transversal do trecho em estudo atinja a MSEA.

\subsection{Elaboração dos mapas de zoneamento da planície de inundação}

Finalizadas as análises hidráulicas, os resultados gerados no HEC-RAS são exportados para o software de geoprocessamento para criação dos mapas contendo as informações sobre as seções transversais, velocidades, zona de passagem de cheia, entre outras. Utilizando ferramenta de geoprocessamento, são realizadas as seguintes tarefas:

- Geração de modelo triangular (Triangular Irregular Network - TIN), que define a elevação da superfície da água em cada local do mapa;

- Subtração da camada contendo as informações de elevação do terreno da camada contendo as informações de elevação da linha d'água. Desta maneira, nos locais nos quais a elevação da linha d'água é superior à elevação do terreno, são criadas as zonas ZPC e ZRI; 
- Carregamento de outros planos de informação (curvas de nível, cadastro de habitações, sistema viário, hidrografia, etc.) para análise em conjunto com as manchas de inundação, de modo a verificar a consistência dos resultados.

Podem ser necessárias correções de inconsistências geradas em razão da diferença entre a representação da geometria da calha do rio no modelo hidráulico e a topografia representada pelas curvas de nível e outros planos de informação disponíveis. 0 primeiro tipo de inconsistência diz respeito aos espaços representados como não inundados confinados no interior de um meandro, que não são representados por nenhuma seção transversal, e que caracterizam uma falha de representação. Segundo Earles et al. (2004), estas falhas não são incomuns, pois o modelo HEC-RAS é extremamente sensível ao posicionamento e espaçamento das seções, assim, diversas iterações podem ser necessárias para delimitar as zonas de inundação com maior precisão. Para resultados mais rápidos, tais falhas dentro das manchas de inundação podem ser corrigidas manualmente no ambiente de geoprocessamento, com base na simples análise visual.

O segundo tipo de inconsistência pode ser observado ao se analisar as manchas de inundação (ZRI e ZPC) produzidas pelo modelo hidráulico sobre outros planos de informação. Como a linha que define o limite da inundação é definida entre seções no HEC-RAS por meio de interpolação linear, é comum que a borda da mancha de inundação intercepte edificações, ruas, açudes, curvas de nível, entre outras feições do terreno, o que fica mais evidente à medida que se aumenta a escala de visualização. Assim, é recomendado ajustar manualmente a linha do limite da inundação, procurando acompanhar curvas de nível e contornando feições que não deveriam ser cruzadas pelo limite da inundação na escala de análise. A realização deste ajuste torna o produto do mapeamento mais consistente e evita que o trabalho técnico perca credibilidade junto à população e gestores públicos não especialistas no tema. De qualquer forma, são esperados ajustes de detalhes no limite de inundação ao longo das rodadas de discussão do zoneamento com a população, cujo olhar, do ponto de vista do proprietário, tende a ser rigoroso.

\subsection{Avaliação urbanística}

Os critérios para a definição de zoneamento de cheias estão intimamente ligados ao uso do solo urbano. Apesar da componente hidrológica ser a orientadora quanto ao risco de inundação de uma determinada área, a transformação da peça técnica (estudo hidráulico) em resultado (redução do risco) depende da adequada avaliação urbanística, traduzida pelo Plano Diretor de Desenvolvimento Urbano (PDDU). Claro que, para uma efetiva redução de risco, há ainda uma instância de gestão pública, no sentido de orientar e fomentar o uso de mecanismos financeiros, jurídicos e políticos previstos na legislação para tornar viáveis as peças técnicas de planejamento urbano, como o IPTU progressivo no tempo, a contribuição de melhoria, a transferência do direito de construir, operações urbanas consorciadas, entre outros instrumentos. Ou seja, a redução do risco depende da consideração da componente hidrológica no planejamento do ordenamento territorial orientado pelo PDDU e da consequente gestão do ordenamento que garanta a sua aplicação na materialidade.

Em uma análise restrita do PDDU vigente no município, a avaliação urbanística do ZPI contempla os seguintes passos:

- $\quad$ Sobreposição dos mapas da ZPC e da ZRI sobre o mapa do zoneamento de uso do solo do PDDU;

- Verificação das combinações entre ZPC e ZRI e as zonas de uso do solo (ex. zona mista, zona industrial, etc.);

- Definição de novo regramento de atividades permitidas para cada uso do solo inserido em ZPC ou ZRI;

- Definição de cotas de segurança e padrões construtivos para as ocupações permitidas na ZRI.

Ainda, com base em um mapa vetorial de cadastro imobiliário, é possível verificar quais polígonos pertencentes a cada uso apresentam ocupação consolidada e quais ainda estão cobertos por vegetação, caso se deseje diferenciar tais condições.

\section{6. Área de estudo}

O rio Caí, localizado na região nordeste do Estado do Rio Grande do Sul, é um dos contribuintes do rio Guaíba e sua bacia hidrográfica tem área aproximada de $5 \mathrm{mil} \mathrm{km}^{2}$. Segundo SOP/Metroplan (Estado do Rio Grande do Sul, 2014), a população estimada na bacia em 2008 era de cerca de 537 mil habitantes, o que representa 5\% da população do estado do Rio Grande do Sul. 0 trecho em 
estudo, do baixo rio Caí, atravessa os municípios de Harmonia, Montenegro, Pareci Novo e São Sebastião do Caí, como pode ser visto na Figura 3. Este trecho, com uma extensão de 176,6 km e uma declividade média de $0,00015 \mathrm{~m} / \mathrm{m}$, é o que apresenta os principais problemas de inundação por ter característica de planície e sofrer efeito de remanso do lago Guaíba.

Em 2014, a Fundação Estadual de Planejamento Metropolitano e Regional (Metroplan), vinculada à Secretaria de Obras (SOP) do Estado do Rio Grande do Sul, elaborou o estudo denominado "Alternativas para Minimização do Efeito das Cheias do Trecho Baixo do Rio Caí - RS" (Estado do Rio Grande do Sul, 2014). Este estudo desenvolveu a análise hidrológica e hidráulica do trecho do rio Caí localizado entre as cidades de Harmonia, São Sebastião do Caí, Pareci Novo e Montenegro, estado do Rio Grande do Sul, Brasil. Como resultados, foram apresentados o mapeamento das áreas inundáveis do trecho baixo do rio Caí, bem como alternativas de proteção contra cheias. A partir dos dados de cobertura aerofotogramétrica, topobatimetria, hidrologia e simulação hidráulica do trecho baixo do rio Caí provenientes deste projeto (Estado do Rio Grande do Sul, 2014), foram desenvolvidos os estudos para o zoneamento de passagem de cheia apenas na cidade de Montenegro, objeto do presente trabalho.

A delimitação de zonas de passagem de cheia foi realizada para todas as áreas urbanas ao longo do trecho baixo do rio Caí. No entanto, o trecho cujo ZPI é apresentado como estudo de caso neste artigo, com a avaliação urbanística sobre os resultados da simulação hidráulica, está situado entre os municípios de Montenegro e Capela de Santana, compreendendo a área urbana do município de Montenegro (destacado na Figura 3).

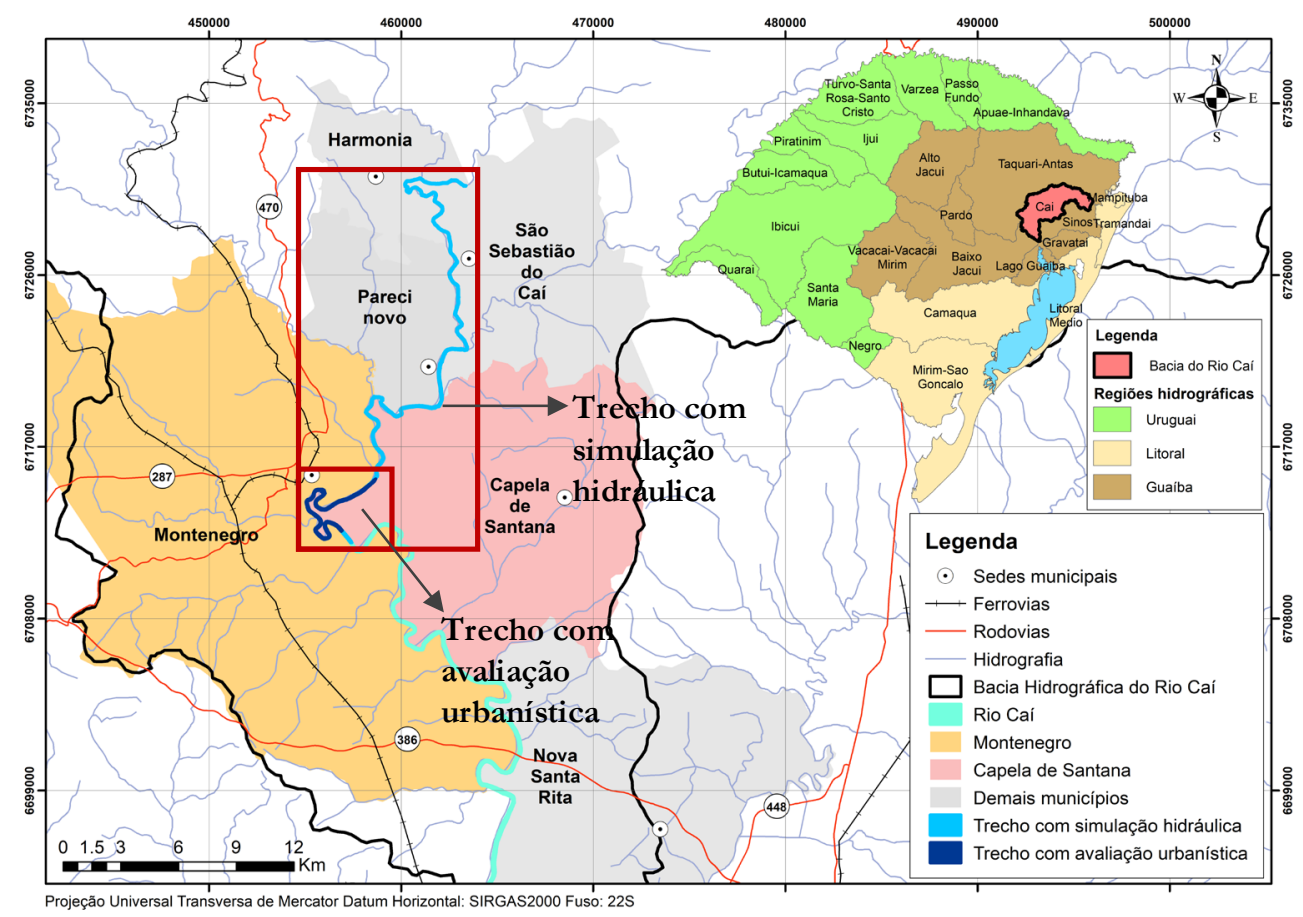

Figura 3. Localização da cidade de Montenegro e o trecho baixo do rio Caí, no Rio Grande do Sul.

\subsection{Dados utilizados}

Foram utilizados dados planimétricos e altimétricos na escala 1:2.000 (curvas de nível espaçadas em 1 metro) do trecho, com distância de $1.500 \mathrm{~m}$ para cada lado do rio, oriundos da restituição aerofotogramétrica proveniente do estudo de SOP/Metroplan (Estado do Rio Grande do Sul, 2014). Além disto, o referido estudo forneceu 27 seções transversais do rio Caí, que serviram de base para interpolação linear de seções batimétricas espaçadas em 30 m entre si para obtenção da conformação da calha do rio no HEC-RAS.

As condições de contorno do modelo hidráulico utilizadas, também foram obtidas do estudo de SOP/Metroplan (Estado do Rio Grande do Sul, 2014): (1) vazão de $2073 \mathrm{~m}^{3} \cdot \mathrm{s}^{-1}$ na seção de montante, para 100 anos de tempo de retorno; (2) vazões de contribuição lateral estimadas durante a calibração do modelo; e (3) nível da seção de jusante de 2,76 m, obtido através da estação Praça da Harmonia para um tempo de retorno de 100 anos. Destaca-se que, apesar de a cheia do rio Caí não ser, do ponto 
de vista estatístico, totalmente independente da variação de nível no lago Guaíba, entende-se que a consideração de 100 anos de tempo de retorno para ambos é bastante crítica e rara, podendo se aproximar da recorrência decamilenar. No entanto, esta foi a avaliação do órgão responsável pelos estudos (Estado do Rio Grande do Sul, 2014), mantida no presente trabalho.

\section{RESULTADOS E DISCUSSÃO}

Para organização da apresentação, os resultados foram divididos em simulações hidráulicas e avaliação urbanística.

\subsection{Simulações hidráulicas}

Inicialmente, verificou-se a necessidade de segmentação do trecho em estudo. Simulações preliminares mostraram que, quando testada uma largura da zona de passagem da cheia constante em todo o trecho (métodos 1 ou 2 do HEC-RAS), ao maximizar a sobre-elevação (dentro do limite estabelecido para teste, de $35 \mathrm{~cm}$ ) a jusante, o limite de sobre-elevação era excedido nos municípios situados a montante. Ao se respeitar o limite a montante, ocasionava-se uma zona de passagem da cheia de pouca profundidade e sobre-elevações nulas em várias seções a jusante. Por outro lado, caso se respeitasse a máxima sobre-elevação definida em todas as seções do trecho (método 4 do HEC-RAS), os valores de largura da ZPC apresentaram variações bruscas de seção a seção e grande amplitude, variando de $150 \mathrm{~m}$ a mais de $4400 \mathrm{~m}$, o que poderia dificultar a apropriação do estudo hidráulico na ordenação do uso do solo das cidades, indicando a necessidade de segmentação.

No intuito de evitar conflitos e facilitar a futura implantação do zoneamento em questão, foram utilizados os limites municipais de Harmonia, Pareci Novo e Montenegro como base para a divisão, gerando 3 segmentos, em acordo com a divisão política dos municípios.

De modo a verificar a sensibilidade do zoneamento (largura da ZPC e sobre-elevação nas seções), para o tempo de retorno de 100 anos e com base na segmentação definida entre os municípios, o modelo hidráulico foi executado para 3 diferentes MSEA: 0,15, 0,35 e 0,55 m. A Tabela 2 apresenta os resultados desta análise.

Tabela 2. Valores de sobre-elevação da linha d'água e de larguras da ZPC em cada segmento do trecho simulado nos cenários de MSEA

\begin{tabular}{cc|c|cc|c}
\hline \multirow{2}{*}{$\begin{array}{c}\text { MSEA } \\
(\mathbf{m})\end{array}$} & $\begin{array}{c}\text { Variáveis de } \\
\text { análise }\end{array}$ & Harmonia & $\begin{array}{c}\text { Pareci Novo/São } \\
\text { Sebastião do Caí }\end{array}$ & $\begin{array}{c}\text { Montenegro / } \\
\text { Capela de } \\
\text { Santana }\end{array}$ & $\begin{array}{c}\text { Total (todo o } \\
\text { trecho em } \\
\text { estudo) }\end{array}$ \\
\hline \multirow{3}{*}{0,15} & Largura da ZPC & $1400 \mathrm{~m}$ & $2400 \mathrm{~m}$ & $2300 \mathrm{~m}$ & \\
\cline { 2 - 6 } & SE media & $0,09 \mathrm{~m}$ & $0,10 \mathrm{~m}$ & $0,02 \mathrm{~m}$ & $0,07 \mathrm{~m}$ \\
\cline { 2 - 6 } & SE máxima & $0,13 \mathrm{~m}$ & $0,15 \mathrm{~m}$ & $0,11 \mathrm{~m}$ & $0,15 \mathrm{~m}$ \\
\hline \multirow{3}{*}{0,35} & Largura da ZPC & $1000 \mathrm{~m}$ & $1800 \mathrm{~m}$ & $1500 \mathrm{~m}$ & \\
\cline { 2 - 6 } & SE media & $0,25 \mathrm{~m}$ & $0,25 \mathrm{~m}$ & $0,08 \mathrm{~m}$ & $0,19 \mathrm{~m}$ \\
\cline { 2 - 6 } & SE máxima & $0,35 \mathrm{~m}$ & $0,35 \mathrm{~m}$ & $0,24 \mathrm{~m}$ & $0,35 \mathrm{~m}$ \\
\hline \multirow{3}{*}{$0,55^{3}$} & Largura da ZPC & $800 \mathrm{~m}$ & $1500 \mathrm{~m}$ & $1000 \mathrm{~m}$ & \\
\cline { 2 - 6 } & SE média & $0,40 \mathrm{~m}$ & $0,45 \mathrm{~m}$ & $0,19 \mathrm{~m}$ & $0,34 \mathrm{~m}$ \\
\cline { 2 - 6 } & SE máxima & $0,54 \mathrm{~m}$ & $0,56 \mathrm{~m}$ & $0,46 \mathrm{~m}$ & $0,56 \mathrm{~m}$ \\
\hline
\end{tabular}

Observa-se que no município de Harmonia, variando-se a MSEA de 0,15 para 0,35 m, a largura da ZPC é reduzida em $400 \mathrm{~m}$. Já quando a MSEA varia de 0,35 para 0,55 m, a largura da ZPC é reduzida em apenas $200 \mathrm{~m}$, metade da redução observada entre 0,15 e 0,35 m. Este mesmo padrão é observado para o município de Montenegro, no qual a largura da ZPC é reduzida em $800 \mathrm{~m}$ variando a MSEA de 0,15 para 0,35 m, mas variando-se a MSEA de 0,35 para 0,55, a redução é de apenas $500 \mathrm{~m}$. No município de Pareci Novo, quando a MSEA é modificada de 0,15 para 0,35 m, a redução da largura

3 Para a análise considerando o valor de MSEA de 0,55 m não foi possível obter valores de largura para ZPC (com dois algarismos significativos) que gerassem exatamente o valor de MSEA de 0,55 em pelo menos uma seção transversal do trecho em estudo. Os valores de MSEA mais próximos de $0,55 \mathrm{~m}$ obtidos foram $0,53 \mathrm{~m}$ e 0,56 $\mathrm{m}$. Ao final, optou-se por utilizar o valor de 0,56 $\mathrm{m}$ para apresentação dos resultados por ser o valor mais próximos de $0,55 \mathrm{~m}$ 
da ZPC é de 600 m. e variando-se a MSEA é de 0,35 para 0,55 m, a redução é de apenas 300 m, metade da redução apresentada entre 0,15 e 0,35 m. Esta análise indica que a modificação da largura da ZPC no trecho de Pareci Novo possui uma maior influência nos valores de sobre elevação da linha d'água. Esta hipótese também é sustentada pelo fato que de este segmento apresenta o maior número de seções transversais atingindo a MSEA em todas as análises.

Em suma, observou-se que, ao variar em $20 \mathrm{~cm}$ o valor de MSEA, de 0,15 para 0,35 m, as larguras de ZPC no trecho todo reduziram, em média, em 29\%. Variando MSEA nos mesmos $20 \mathrm{~cm}$, de 0,35 para 0,55 m, observou-se uma redução menor na largura da ZPC, de 23\%. Ou seja, o decréscimo marginal na ZPC é menor ao se aumentar o MSEA, implicando em um maior impacto a montante (sobre-elevação em $20 \mathrm{~cm}$ ) para um benefício menor em termos de área urbana disponível para ocupação. Por este motivo, foi adotado o valor intermediário de MSEA, de 0,35 m, para delimitação da ZPC. Assim, a largura máxima da zona de passagem de cheia resultou como sendo de 1 km no município de Harmonia, 1,8 km no município de Pareci Novo e 1,5 km no município de Montenegro.

A zona de inundação e a zona de passagem de cheia foram então adicionadas ao mesmo mapa base, permitindo a visualização de ambas no contexto local. A Figura 4 mostra parte da região de Montenegro com a zona de inundação e a zona de passagem de cheia para 100 anos de tempo de retorno.

Observou-se que, em cerca de $90 \%$ das seções transversais, a área inundada atinge o limite do modelo digital do terreno utilizado, indicando que a ZRI pode possuir uma largura ainda maior que a estimada por este modelo. Para contornar esta limitação seria necessário expandir a área da restituição fotogramétrica nestes locais e/ou aumentar o número de seções transversais do trecho.

Observa-se na Figura 4, formas triangulares no interior dos meandros, além do alcance das seções transversais, em que o terreno não aparece inundado, como se fossem ilhas. Estas formas são falhas na obtenção das áreas inundadas (ZPC e ZRI) que ocorrem em meandros e são inerentes à representação unidimensional do modelo hidráulico, através de seções transversais. Com base nas informações de edificações, infraestrutura, rede de drenagem e, principalmente, curvas de nível, provenientes da restituição aerofotogramétrica, tais imperfeições foram corrigidas, em um processo manual.

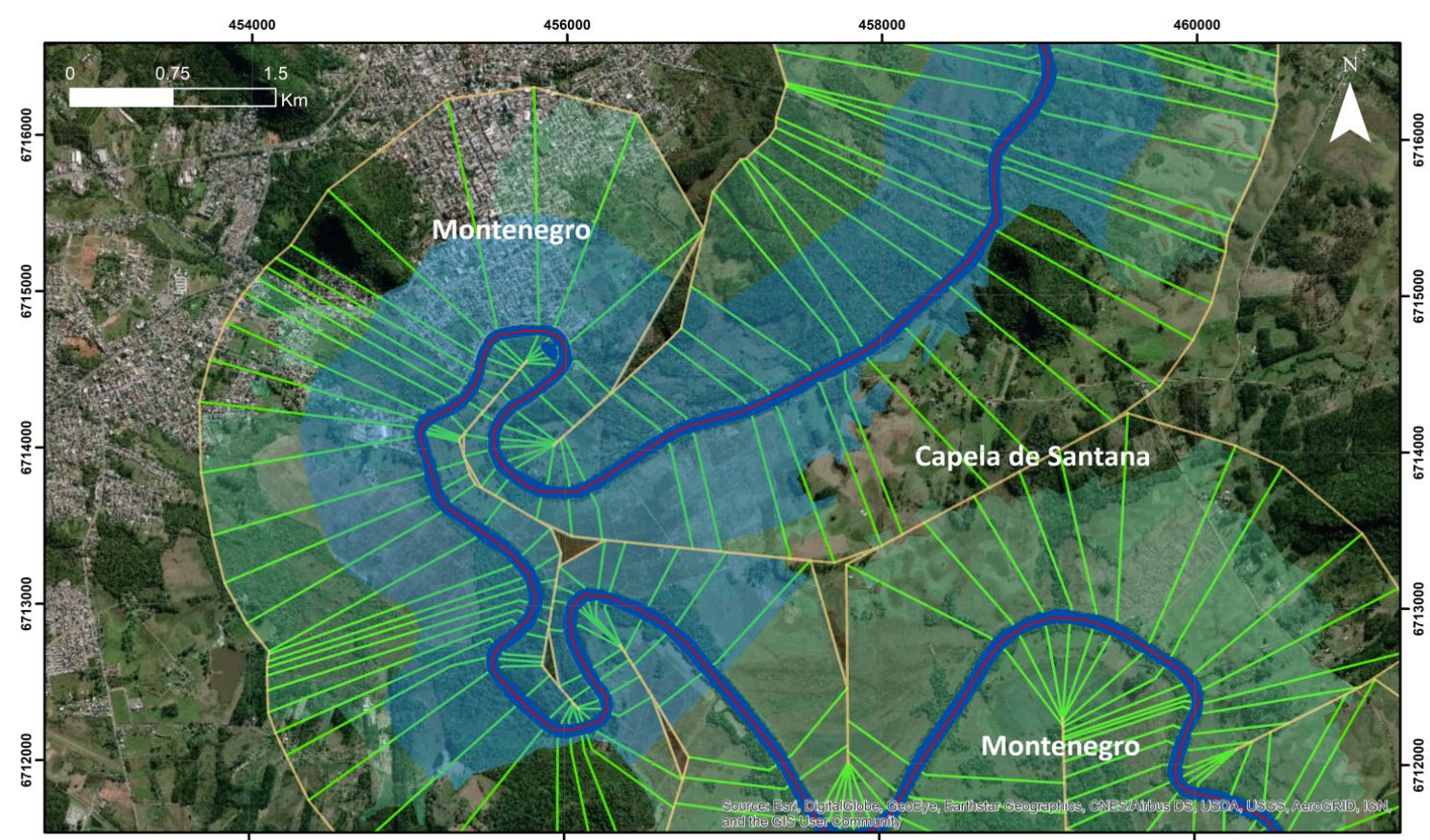

Projeção Universal Transversa de Mercator Datum horizontal: SIRGAS2000 Fuso: 22S

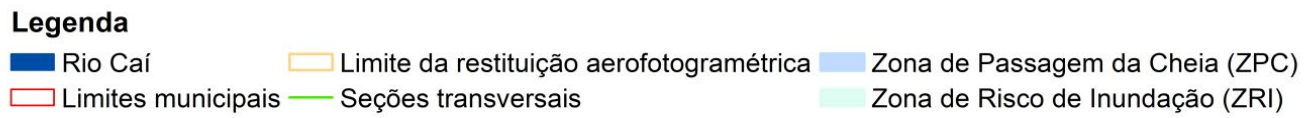

Figura 4. Detalhe da ZPC e da ZRI na cidade de Montenegro. 
Feitas as correções, as zonas 1 e 2 foram sobrepostas aos arquivos vetoriais da restituição para gerar o mapa de ZPI, conforme apresenta a Figura 5 para a cidade de Montenegro. Observa-se na Figura 5, que além da zona de passagem da cheia (ZPC), da zona de risco de inundação (ZRI), e da ZPCO, outra categoria foi criada, derivada da ZRI, a Zona de Potencial Passagem da Cheia de rio tributário (ZPPC). No caso da ZPPC, apesar de o mapeamento indicar que esta zona tem risco de inundação, mas está fora da ZPC, observa-se que se trata do vale de um tributário do rio simulado (neste caso, o rio Caí). Como o tributário não foi simulado com o HEC-RAS, a definição de seu vale inundado pelas águas do Caí como "zona de potencial passagem da cheia" é uma precaução. Uma simulação específica do tributário, considerando o efeito de remanso do rio Caí, permitirá definir com precisão sua ZPC. A Tabela 3 apresenta a descrição e usos recomendados para cada uma das zonas.

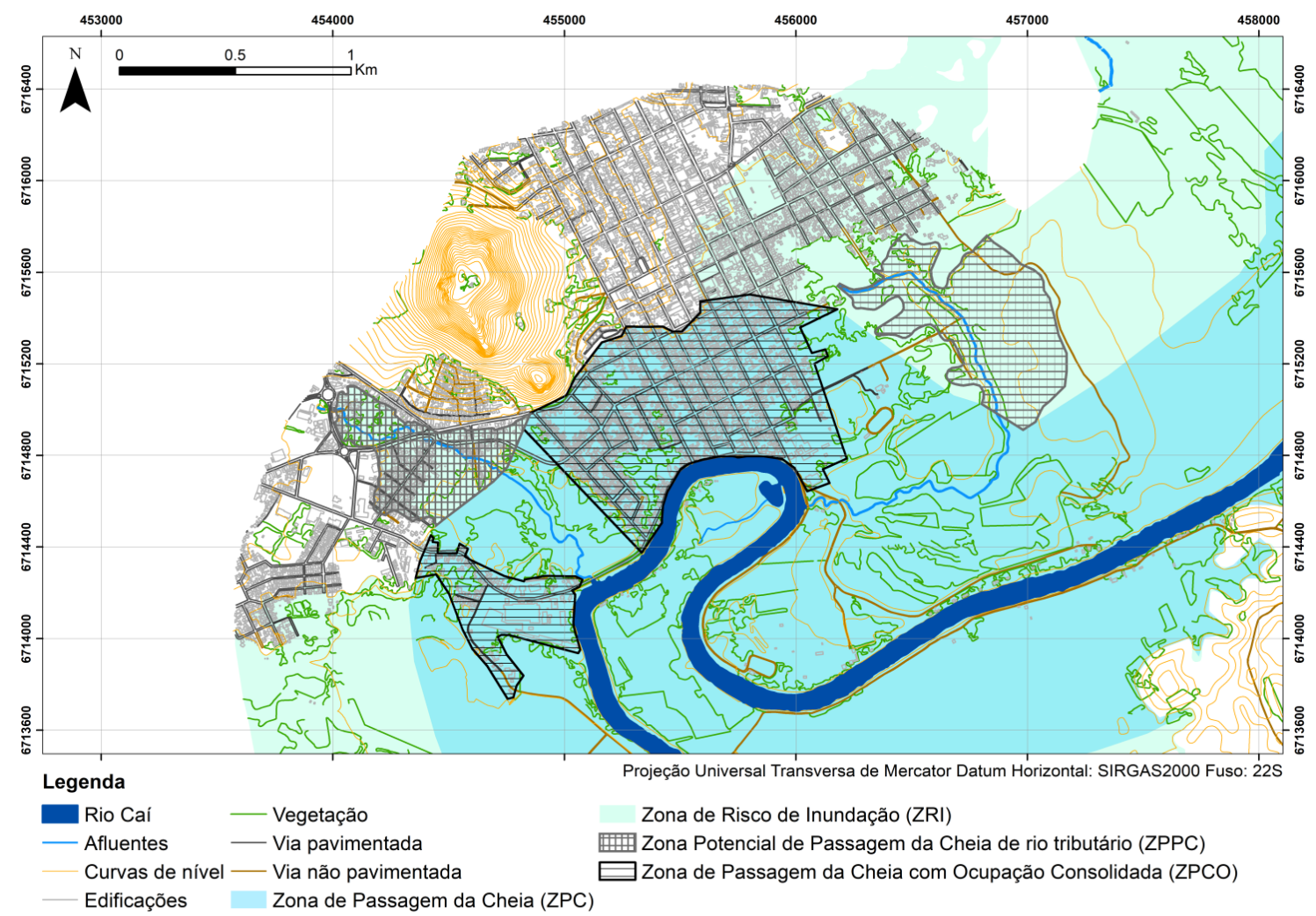

Figura 5. Zoneamento das áreas de inundação da cidade de Montenegro no trecho baixo do rio Caí, RS.

Tabela 3. Definição de zonas e de usos recomendados no ZPI do município de Montenegro-RS

\begin{tabular}{|c|c|c|}
\hline Identificação & Definição & Usos do solo recomendados \\
\hline $\begin{array}{c}\text { ZPC - Zona de } \\
\text { Passagem da Cheia }\end{array}$ & $\begin{array}{l}\text { Zonas sujeitas à inundação pela } \\
\text { cheia de referência, determinada } \\
\text { por métodos detalhados de } \\
\text { cálculo; a elevação da linha d'água } \\
\text { e a velocidade do fluxo são } \\
\text { conhecidas. Nesta zona, o fluxo } \\
\text { não apresenta velocidades e } \\
\text { profundidades significativas. }\end{array}$ & $\begin{array}{l}\text { Esta zona não deve receber novas construções } \\
\text { que obstruam a passagem do fluxo; deve-se } \\
\text { considerar, no entanto, o caso de construções } \\
\text { que necessitam estar localizadas nestas áreas, } \\
\text { tais como aquelas relacionadas a atividades } \\
\text { portuárias. Obras que não interrompam o } \\
\text { fluxo, como por exemplo, linhas de } \\
\text { transmissão, condutos hidráulicos, campos de } \\
\text { esportes e parques lineares, podem ser } \\
\text { implantadas nesta zona. }\end{array}$ \\
\hline $\begin{array}{l}\text { ZRI - Zona de Risco de } \\
\text { Inundação }\end{array}$ & $\begin{array}{l}\text { Zonas de passagem da cheia de } \\
\text { referência, determinadas por } \\
\text { métodos detalhados de cálculo; } \\
\text { a elevação da linha d'água e a } \\
\text { velocidade do fluxo são } \\
\text { conhecidas. }\end{array}$ & $\begin{array}{l}\text { A ocupação desta área deve ser parcimoniosa, } \\
\text { optando-se preferencialmente por usos que } \\
\text { permitam uma convivência com as cheias sem } \\
\text { a geração de danos e prejuízos significativos. } \\
\text { A ocupação urbana é permitida, desde que } \\
\text { obedecendo à cota estimada para a cheia de } \\
\text { referência e mitigados os riscos de falha dos } \\
\text { sistemas de proteção contra cheias. }\end{array}$ \\
\hline
\end{tabular}




\begin{tabular}{|c|c|c|}
\hline Identificação & Definição & Usos do solo recomendados \\
\hline $\begin{array}{l}\text { ZPCO - Zona de } \\
\text { Passagem da Cheia } \\
\text { com Ocupação } \\
\text { Consolidada }\end{array}$ & $\begin{array}{l}\text { Zonas inseridas na ZPC, mas nas } \\
\text { quais existe a ocupação urbana } \\
\text { consolidada. }\end{array}$ & $\begin{array}{l}\text { Apesar das características hidráulicas da cheia } \\
\text { nesta zona serem similares a da ZPC, a ocupação } \\
\text { urbana já consolidada permite esta zona ser } \\
\text { ocupada com as mesmas ressalvas da ZRI. }\end{array}$ \\
\hline $\begin{array}{l}\text { ZPPC - Zona de } \\
\text { Potencial Passagem } \\
\text { da Cheia de rio } \\
\text { tributário }\end{array}$ & $\begin{array}{l}\text { Zonas inseridas na ZRI, mas nas } \\
\text { quais há indícios de que possa ser } \\
\text { zona de passagem da cheia de } \\
\text { tributário. } 0 \text { risco de inundação } \\
\text { não está determinado com } \\
\text { precisão, pois a análise hidráulica } \\
\text { detalhada ainda não foi realizada. }\end{array}$ & $\begin{array}{l}\text { Apesar das características hidráulicas do } \\
\text { sistema simulado indicarem esta zona como } \\
\text { ZRI, o fato dela estar no vale de um tributário } \\
\text { (não representado pelo modelo hidráulico) } \\
\text { confere a esta zona as mesmas restrições da } \\
\text { ZPC, até que seja realizado estudo específico. }\end{array}$ \\
\hline
\end{tabular}

\subsection{Avaliação urbanística}

De modo a subsidiar a elaboração de uma proposta do ZPI do município de Montenegro, as análises urbanísticas foram realizadas com base no Plano Diretor de Desenvolvimento Urbano (PDDU) do município (Montenegro, 2014) e nos arquivos vetoriais da restituição aerofotogramétrica da Secretaria Municipal da Fazenda.

Analisando-se o zoneamento, uso e ocupação do solo, conforme diretrizes estabelecidas no PDDU (Montenegro, 2007, 2014), apresentado na Figura 6, pode-se observar que uma parte significativa da área urbana da cidade encontra-se no interior da zona de risco de inundações. A própria zona de passagem da cheia contempla parte importante da cidade, englobando toda a área central, incluindo prefeitura municipal, câmara de vereadores, bancos, entre outras instituições relevantes. A área de risco de inundação inclui parte da Zona Residencial (ZR), parte da Zona Industrial e Atacadista (ZIA), parte da Zona de Restrição Ambiental (ZRA), parte da Zona Central (ZC) e igualmente parte dos Setores de Proteção do Cais do Porto (SPCP), parte do Setor Especial de Proteção da Margem do Rio Caí (SEPMRC) e parte do Setor Especial de Proteção dos Morros (SEPM). A partir dessa análise, é possível identificar de que forma o ZPI deverá impactar no zoneamento do PDDU e, no sentido inverso, de que forma o desenvolvimento urbano poderá alterar o zoneamento de passagem das cheias e propor a harmonização de ambas as peças técnicas.

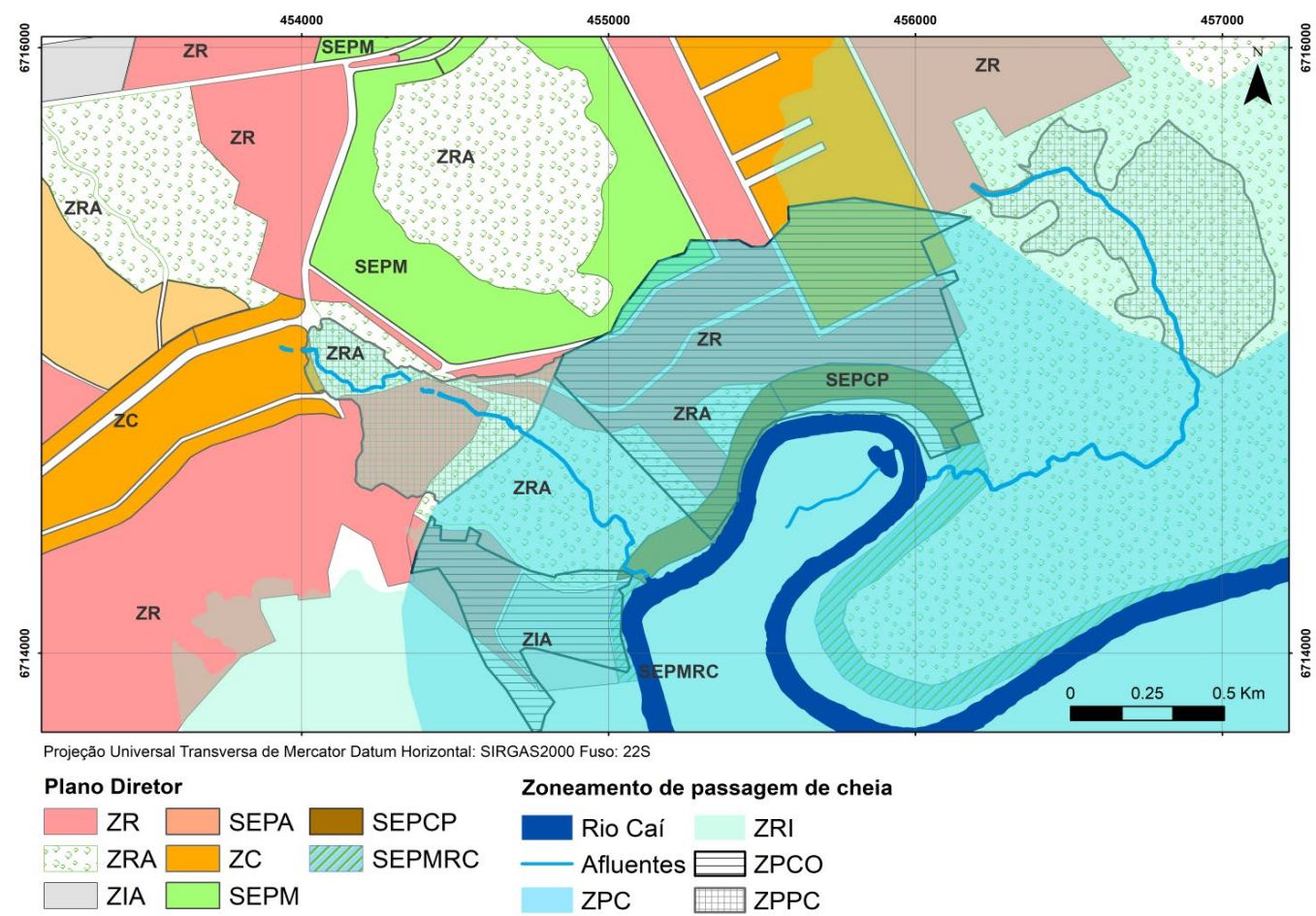

Figura 6. Sobreposição do zoneamento de passagem de cheia elaborado com o Plano Diretor de Desenvolvimento do município de Montenegro. 
Na ZR e na ZIA, destaca-se o objetivo de provimento de infraestrutura básica, na ZR para fins habitacionais e na ZIA para potencializar as condições logísticas. Estas zonas estão parcialmente inseridas na ZPC e na ZRI. São áreas com ocupação consolidada e que requerem ambas, medidas de proteção e prevenção. Da teoria, facilmente se depreende que, na ZRI, seria permitida a continuação da ocupação do solo, desde que obedecendo a cota estimada para a cheia de referência. No entanto, na ZPC a questão exige maior reflexão. Se parte da ZIA e ZR da cidade estão em uma área definida como passagem da cheia, onde não se recomenda qualquer tipo de ocupação que possa sofrer danos ou obstruir o fluxo da cheia, qual a alternativa a ser oferecida? A convivência com a cheia, em uma área urbana consolidada, como na região central de Montenegro, não é recomendada. Para a ocupação existente, restam então duas opções: remoção da ocupação ou proteção por diques. Um estudo de viabilidade (benefício/custo) poderá orientar nessa decisão. No caso de Montenegro, o estudo de SOP/Metroplan (Estado do Rio Grande do Sul, 2014) concluiu que os custos de proteção são menores que os de reassentamento. De qualquer forma, enquanto nenhuma medida é tomada é necessário regrar o uso do solo para o desenvolvimento futuro. Para isso, decidiu-se por estabelecer uma subclasse da ZPC, para áreas inseridas na ZPC com ocupação consolidada (ZPCO), em que, assim como na ZRI, é permitida a construção, desde que tomadas as providências para proteção contra cheia. 0 motivo para a criação desta classe é que, do ponto de vista hidráulico, já há uma obstrução na zona de passagem da cheia, ocasionada pelas edificações existentes. Assim, caso fosse vedada a construção em um terreno circundado de edificações, por este estar na zona de passagem da cheia, estaria sendo imposta penalização àquele proprietário sem qualquer benefício do ponto de vista de prevenção de inundações. Por outro lado, caso o Estado opte por restringir o desenvolvimento em área urbana consolidada na ZPC, instrumentos como a transferência do direito de construir, as operações urbanas consorciadas e a desapropriação com pagamento em títulos da dívida pública, combinados a isenção de IPTU ou ainda incentivos a usos de baixo impacto, poderiam ser aplicados como alternativa para diminuir danos financeiros ao proprietário.

Na ZC a situação é similar, mas pode haver ainda outro desdobramento que apenas a análise do PDDU não permite confirmar. Em uma zona de grande importância social e econômica, como é o centro da cidade, é possível que a relação benefício/custo de uma obra de proteção seja maior do que nos bairros. Neste caso, que é apenas uma hipótese, caso fossem previstos diques de proteção margeando o rio, o zoneamento do PDDU deveria ser revisto quando da implantação das obras, o que iria condicionar a ZPC e a ZRI, cujos limites seriam então definidos pelos diques. Assim, o desenvolvimento urbano poderia impactar no ZPI.

Na ZRA, o PDDU destaca os objetivos que visam preservar a permeabilidade do solo, desestimular a ocupação do solo para que garantam o escoamento das águas e a minimização dos prejuízos decorrentes das enchentes e incentivar o desenvolvimento de áreas de lazer. Neste caso, nas ZRAs situadas na ZPC, os objetivos do zoneamento do PDDU e do ZPI são completamente coincidentes e deverão funcionar perfeitamente. 0 cenário seria alterado apenas caso houvesse pressão por ocupação nestas áreas. Assim, seria razoável propor, para compatibilização entre os dois zoneamentos e respectivos objetivos e diretrizes, a orientação de utilização desta zona para atividades de lazer e preservação, como parques, clubes esportivos, etc.

Quanto aos setores de proteção, destaca-se o SEPCP e o SEPMRC pois estão localizados, por sua própria natureza, dentro da ZPC e apresentam edificações localizadas próximas às margens do Rio Caí. Dentre os objetivos estabelecidos para estes setores destacam-se os que buscam preservar, proteger e recuperar o cais e seu respectivo entorno, assim como estimular o uso do solo para atividades de cultura, lazer e turismo. Estes usos estão de acordo com as diretrizes previstas para ZPC.

\section{CONCLUSÕES}

A falta de critérios técnicos estabelecidos para a elaboração de ZPI foi uma das motivações na proposição de uma metodologia e condicionou as análises realizadas. 0 primeiro fato que se verificou, foi a necessidade de segmentação do trecho do rio Caí em estudo, com 176 km de extensão. Concluímos que não há um parâmetro de referência que possa ser utilizado de forma geral, como um determinado valor de extensão de segmento. Cada caso deve ter uma segmentação própria, dependendo das características topográficas da planície e, se for o caso, da divisão política do território. No rio Caí, nas primeiras tentativas de definir a largura da ZPC, utilizando uma MSEA de 0,35 m, não foi possível obter uma sobre-elevação da linha d'água próxima da MSEA no trecho inteiro para uma largura da ZPC constante. Apesar de a simulação hidráulica sempre considerar o efeito de remanso em todo o trecho, a segmentação contribuiu para diminuir a variabilidade dos valores de sobre-elevação da linha d'água 
e uniformizar as larguras da zona de passagem da cheia. A definição dos limites exatos de cada segmento, no entanto, não seguiu um critério técnico, mas dependeu da divisão política dos municípios no estudo de caso. É apenas uma hipótese, mas, caso a largura da ZPC variasse dentro dos limites de um mesmo município, é possível que houvesse algum tipo impasse na aprovação do ZPI, gerado por conflito entre proprietários de terra afetados por diferentes distâncias do rio em que haveria restrição de ocupação.

Outro critério importante, que não tem uma definição técnica evidente, é a MSEA. Neste estudo de caso, foram testados 3 valores com incrementos de $20 \mathrm{~cm}(0,15,0,35$ e 0,55 m) e houve variação importante nos resultados observados através da largura da ZPC. 0 valor de $0,35 \mathrm{~m}$ foi selecionado por seu incremento para o maior valor do intervalo testado $(0,55 \mathrm{~m})$ ter gerado o menor aumento marginal da largura da ZPC. O valor selecionado, dos testados, é o mais próximo do padrão americano, de 0,30 m. No entanto, a análise realizada não permite a extrapolação do valor de 0,35 m para qualquer outro caso. A recomendação é de que novos estudos para definição de ZPI adotem metodologia similar, de modo a se obter sensibilidade sobre a variação do parâmetro MSEA, quem sabe, levando a definição de um valor de praxe no futuro.

Quanto à análise urbanística, entende-se que as classes e usos recomendados da Tabela 3 possam servir como base para a elaboração de uma metodologia de ZPI com abrangência nacional. Para a aplicação dos resultados do ZPI, visualiza-se duas formas: o ZPI poderia ser um mapa temático do PPDU, cujas recomendações seriam acrescentadas àquelas do zoneamento urbano, ou os mapas do zoneamento do PDDU e do ZPI seriam cruzados, gerando um terceiro mapa com novas classes de zoneamento.

Sobre os mapas de ZPI, a realização de ajustes manuais, em função de características topológicas, parece ter pouco interesse acadêmico ou científico do ponto de vista de engenharia. No entanto, sob a ótica da gestão pública, esta etapa é importante para dar credibilidade ao produto técnico final e permitir que os mapas tenham uma tramitação mais amena nas instâncias decisórias, onde o ZPI será definitivamente incorporado ao PDDU.

Ainda quanto aos aspectos de gestão pública, reconhece-se que a aplicação do zoneamento de cheias tem grande impacto social e econômico, dependendo assim de ampla discussão no âmbito do município. Estudos hidrológicos que forneçam valores de prejuízos com inundações, confrontando os cenários com e sem a aplicação do ZPI, são ferramentas importantes para subsidiar o gestor público. Ressalta-se que a zona de passagem da cheia (ZPC) no estudo de caso, realmente foi definida passando por boa parte da área central da cidade de Montenegro, considerando o cenário atual de desenvolvimento do município. Este resultado, no entanto, não sugere que a solução para as inundações ribeirinhas recorrentes em Montenegro sejam a convivência com as cheias. É apenas um exercício, em que são feitas recomendações de zoneamento do solo urbano caso não seja implantada nenhuma obra de proteção, nos moldes dos diques propostos no estudo de SOP/Metroplan (Estado do Rio Grande do Sul, 2014). Caso fossem implantados os referidos diques de proteção do centro da cidade, novo estudo hidráulico iria ser realizado e os limites da ZPC seriam alterados em todo o trecho. No trecho do rio protegido pelos diques, estes seriam o delimitador da zona de passagem da cheia (ZPC) e também da ZRI (uma vez que a área passaria a ser protegida da cheia de 100 anos de tempo de retorno).

Por fim, conclui-se que, apesar da impossibilidade de definição de valores de referência de extensão de segmentos e valores de MSEA, o estudo contribuiu para a consolidação de procedimento de análise e critérios técnicos para implementação de ZPI no Brasil e, desta forma, para a regulamentação de intervenções sustentáveis, resilientes e com segurança jurídica nas cidades. O zoneamento de planície de inundação, se incorporado aos PDMs, representaria um avanço em direção a criação de ambientes urbanos menos vulneráveis à inundações ribeirinhas, evitando a corroboração do modelo atual, em que as áreas de risco são ocupadas de forma irregular, aumentando os prejuízos com inundações e os custos com mitigação do problema.

\section{REFERÊNCIAS}

Alberta Waterportal Society (2017). How Are Flood Maps Created in Alberta? Recuperado em 11 de fevereiro de 2020, de https://albertawater.com/how-are-flood-maps-created-in-alberta

Agência Nacional de Águas (2014). Atlas de Vulnerabilidade a Inundações (15 p.). Brasília: ANA. Recuperado em 10 de fevereiro de 2020 , de

http://metadados.ana.gov.br/geonetwork/srv/en/resources.get?id=243\&fname=Atlas_de_Vulnerabilidade _a_Inundaes.pdf\&access=private 
Barendrecht, M.H., Viglione, A., Blöschl, G. (2017). A dynamic framework for flood risk. Water Security, 1, 3-11. https://doi.org/10.1016/j.wasec.2017.02.001

Bronstert, A. (2003). Floods and climate change: interactions and impacts. Risk Analysis, 23, 545-557.

Cavalcanti R. C.; Tavares Junior, J. R.; Candeias, A. L. B. (2013). Simulação de mapeamento de riscos de inundações usando dados LIDAR: Estudo de caso da bacia do rio Una - PE. Revista Brasileira de Cartografia, 65(4), 703-716.

City of Calgary. Web portal: Building, planning and business - Flood maps. 2020. Recuperado em 11 de fevereiro de 2020, de https://www.calgary.ca/PDA/pd/Pages/Calgary-Land-Use-bylaw-1P2007/Floodway-floodfringe-maps.aspx

Demir, V., \& Kisi, O. (2016). Flood hazard mapping by using geographic information system and hydraulic model: mert River, Samsun, Turkey. Hindawi. Advances in Meteorology, 2016.

DNIT. (2006). Manual de Drenagem de Rodovias. Departamento Nacional de Infraestrutura de Transportes. Diretoria de Planejamento e Pesquisa. Coordenação Geral de Estudos e Pesquisa. Instituto de Pesquisas Rodoviárias - IPR 724 (2. ed.). Rio de Janeiro.

DRIEE. (2020). Plans de prévention des risques inondation (PPRI). Direction Régionale et Interdépartementale de l'Environnement et de l'Énergie. Préfet de la Région d'Ile-de-France. Recuperado em 14 de fevereiro de 2020, de http://www.driee.ile-de-france.developpement-durable.gouv.fr/plans-de-prevention-des-risquesinondation-ppri-r375.html

Earles, T. A., Wright, K. R., Brown, C., \& Langan, T. E. (2004). Los alamos forest fire impact modeling. Journal of the American Water Resources Association, 40, 371-384.

Estado do Rio Grande do Sul. Secretaria de Obras Públicas Desenvolvimento e Irrigação - SOP. Fundação Estadual de Planejamento Metropolitano e Regional - METROPLAN. (2014). Alternativas para Minimização do Efeito das Cheias do Trecho Baixo do Rio Caí - RS. de www.metroplan.rs.gov.br/conteudo/1890/?Relat\%C3\%B3rios_do_projeto_para_download

Eximap. (2007). Handbook on good practices for flood mapping in Europe. European Commission. Recuperado em 12 de fevereiro de 2020, de https://ec.europa.eu/environment/water/flood_risk/flood_atlas/

Federal Emergency Management Agency (1998). Managing Floodplain Development Through the National Flood Insurance Program. Recuperado em 31 de março de 2020, de https://www.fema.gov/medialibrary/assets/documents/6029

Federal Emergency Management Agency (2019). Guidance for Flood Risk Analysis and Mapping: Floodway Analysis and Mapping. Recuperado em 15 de fevereiro de 2020, de https://www.fema.gov/media-librarydata/15780629577930274cb6a7a3801a07a3db7916e64e80d/FloodwayAnalysis_and_Mapping_Nov_2019.pdf

Ferreira, M. T. S. (2019). Mapeamento e avaliação do grau de risco de inundação em áreas urbanas (Dissertação de mestrado). Universidade Federal do Rio Grande do Norte, Centro de Ciências Exatas da Terra, Programa de Pós-graduação em Ciências Climáticas.

Government of British Columbia (2020). Flood Hazard Land Use Management. The official website of the Government of British Columbia. Recuperado em: 11 de fevereiro de 2020, de https://www2.gov.bc.ca/gov/content/environment/air-land-water/water/drought-flooding-dikesdams/integrated-flood-hazard-management/flood-hazard-land-use-management/floodplain-mapping

Green, C.H.; Parker, D.J.; Tunstall, S.M. (2000). Assessment of Flood Control and Management Options. Thematic Review IV.4 prepared as an input to the World Commission on Dams.

Hora, S. B., \& Gomes, R. L. (2009). Mapeamento e avaliação do risco a inundação do Rio Cachoeira em trecho da área urbana do Município de Itabuna/BA. Sociedade \& Natureza, Uberlândia, 21(2), 57-75.

Kourgialas, N. N., \& Karatzas, G. P. (2011). Flood management and a GIS modelling method to assess floodhazard areas - A case study. Hydrological Sciences Journal, 56, 212-225.

Länder-Arbeitsgemeinschaft Wasser 2006. Flood hazard map guidelines of the German Working Group of the Federal States on Water Issues. Bund. Germany.

Leite, M. E., \& Rocha, A. M. (2016). Mapeamento da susceptibilidade à inundação em áreas urbanas: o caso da cidade de Montes Claros-MG. Geosul, Florianópolis, 31(62), 125-150.

Menegasso, J. D. (2019). Mapeamento do risco de inundação na bacia hidrográfica do Rio Belo, Orleans, SC (Dissertação de mestrado). Universidade do Extremo Sul Catarinense, Programa de Pós-Graduação em Ciências Ambientais, Criciúma. 
Metroplan. (2018a). Estudo de alternativas e projetos para minimização do efeito das cheias na bacia do rio dos Sinos. Porto Alegre, RS: Fundação Estadual de Planejamento Metropolitano e Regional.

Metroplan. (2018b). Estudo de alternativas e projetos para minimização do efeito de cheias e estiagens na bacia do rio Gravataí. Porto Alegre, RS: Fundação Estadual de Planejamento Metropolitano e Regional.

Ministry of Housing Communities \& Local Government. (2014). Guidance: Flood risk and coastal change. Recuperado em 03 de fevereiro de 2020, de https://www.gov.uk/guidance/flood-risk-and-coastalchange\#flood-zone-and-flood-risk-tables

Missouri Department of Transportation (2019) Engineering Policy Guide. Item 748.8 - Development in floodplains. Recuperado em 07 de fevereiro de 2020, de https://epg.modot.org/index.php?title=748.8_Development_in_Floodplains\&oldid=46426

Montenegro. (2007). Lei Complementar n 4.759 de 6 de novembro de 2007. Reestrutura o Plano Diretor de Desenvolvimento do Município de Montenegro (PDDMM).

Montenegro. (2014). Lei Complementar no 5.883 de 13 de janeiro de 2014. Dispõe sobre o zoneamento, uso e ocupação do solo do Município de Montenegro.

Murray, D. (2017). Locally, Regionally, Provincially or Nationally: What is the best way to manage flood risk? CWRA National Conference. Lethbridge, Alberta.

Natural Resources Canada (2018). Federal Flood Mapping Framework. Public Safety Canada. General Information Product 112e. (ed. version 2.0). (26 p.) https://doi.org/10.4095/308128. Recuperado em: 14 de fevereiro de 2020 , de http://ftp.geogratis.gc.ca/pub/nrcan_rncan/publications/ess_sst/308/308128/gip_112_v2_0_en.pdf

Nut, N., \& Plermkamon, V. (2015). Floodplain mapping using HEC-RAS and GIS in Nam Phong River Basin, Thailand. International Journal of Environmental and Rural Development, 6, 153-158.

Patel, C. G., \& Gundaliya, P. J. (2016). Floodplain delineation using HEC-RAS Model: A case study of Surat City. Open Journal of Modern Hydrology, 6, 34-42.

Pohlmann, P. (2016). Riscos e legislação: método integrado para proteção de áreas urbanas inundáveis, um estudo em Rolante, RS. (Dissertação de mestrado). Universidade Federal do Rio Grande do Sul, Faculdade de Arquitetura, Programa de Pós-Graduação em Planejamento Urbano e Regional, Porto Alegre, RS.

Prefeitura Municipal de Taquara. (2018). Plano estratégico de manejo de águas pluviais e prevenção de inundações urbanas de Taquara - RS. Zoneamento da Planície de Inundação. Apresentação ppt. Recuperado em: 10 de julho de 2020, de: www.taquara.rs.gov.br/download_anexo/Zoneamento\%20da\%20Planície\%20de\%20Inundação.pdf

Rezende, P. S., \& Marques, D. V. (2017). Mapeamento de riscos a inundação na área urbana de Paracatu - MG. XVII Simpósio Brasileiro de Geografia Física Aplicada. Campinas, SP.

Righi, E. (2016). Metodologia para zoneamento de risco a inundações graduais. (Tese de doutorado). Universidade Federal do Rio Grande do Sul, Instituto de Geociências, Programa de Pós-Graduação em Geografia, Porto Alegre, RS.

Robaina, L. E. S. (2008). Espaço urbano: relação com os acidentes e desastres naturais no Brasil. Ciência e Natura, 30(2), 93-105.

Serviço Geológico do Brasil (2020). Prevenção de Desastres. Produtos por Estado - Cartas de Suscetibilidade a Movimentos Gravitacionais de Massa e Inundações. Recuperado em: 06 de julho de 2020, de www.cprm.gov.br/publique/Gestao-Territorial/Prevencao-de-Desastres/Produtos-por-Estado---Cartas-deSuscetibilidade-a-Movimentos-Gravitacionais-de-Massa-e-Inundacoes-5384.html

Silva, P. V. R. M., Cardoso Junior, R. A. F, \& Noronha, G. C. (2016). Mapeamento e análise de risco de inundação da bacia do rio Paraíba/AL: estudo de caso. Sistemas \& Gestão, 11, 431-443.

Sole, A., Giosa, L., Nolè, L., Medina, V., \& Bateman, A. (2008). Flood risk modelling with LiDAR technology. WIT Transactions on Ecology and the Environment, 118, 27-36.

Surminski, S., \& Eldridge, J. (2014). Flood insurance in England-An assessment of the current and newly proposed insurance scheme in the context of rising flood risk. Working Paper $\mathrm{N}^{\circ} 161$ \& Grantham Research Institute on Climate Change and the Environment Working Paper $\mathrm{N}^{\circ} 144$. Centre for Climate Change Economics and Policy.

Tate, E. C., \& Maidment, D. (1999). Floodplain mapping using HEC-RAS and ArcView GIS. Bureau of Engineering Research, University of Texas, Austin.

Tucci, C. E. M. (2007). Inundações Urbanas (393 p.). Porto Alegre: ABRH/RHAMA. 
United Kingdom Environment Agency - EA. (2016). Flooding and extreme weather. Disponível em: www.gov.uk/government/organisations/environment-agency. Acesso em: 30 de setembro de 2016.

United States Army Corps of Engineers - USACE. (2016). Hydrologic Engineering Center - River Analysis System (HEC-RAS) User's Manual (Version 5).

Water Resources Council (1971). Regulation of flood hazard areas to reduce flood losses. Washington-DC.

\section{Contribuição dos autores}

Dante Gama Larentis: Concepção da publicação, orientador das simulações hidráulicas e análises urbanísticas.

Marianni Nogare: execução das simulações hidráulicas.

Carlos Eduardo Morelli Tucci: revisão geral e orientação da publicação.

Patricia Pohlmann: participação na avaliação urbanística e revisão. 